\title{
III. Historical Issues, Theoretical Perspectives
}

\section{Some Case Studies}

0.-This third part of the present study will highlight specific configurations that emerged in the course of the investigations of the DramaNet research team and which are relevant to the theoretical issues discussed in Part I. These configurations will be considered in a very concise fashion, leaving all more detailed discussions to the books or articles written by the junior scholars who worked with me.-As already announced in the introduction, there is one longer chapter of this third section that will polemically engage the concept of "national literatures", including its present-day derivatives: postcolonial and hybridity theories. But first, I should like to prepare the terrain by looking at a number of particularly interesting constellations of cultural material circulating in the net.

1.-One major difficulty for a theory of global literature as proposed here lies in finding a satisfactory way of generalizing observations derived from the analysis of European practices such that they apply beyond a European context. Is it possible to conceptualize the circulation of early modern European dramatic material to the East, to India and Japan, by means of configurations comparable to intra-Western processes of transculturation? At first blush, one may be inclined to answer the question affirmatively. Terms such as "within" or "outside" of Europe are concepts based on arbitrary delineations, not objective realities. Transculturation is as frequently linked to physical constraints (conquest, imperialism) or ideological subversion (missionary activities) within a continent as it is beyond. What is more, cultural distance is a relative phenomenon. It is contingent upon the level of abstraction involved. As Claude Levi-Strauss showed, it does not exist in the sphere of mythical patterns. Cultural material in the highly organized form of dramatic texts or performance practices is by no means abstract. But it is open to undergo processes of adoption and adaptation. Within such a potentially paradoxical context, the possibility that cultural difference informs different processes of appropriation should not be discarded at the outset.

Questions emerging with regard to non-Western cultures may specifically concern differing concepts of what "theater" consists of. "Occidental" theater is multi-medial, but it relies mainly on language in order to convey messages. This applies all the more to early modern European drama, in particular when compared to its medieval counterpart. What becomes of "occidental" drama when it is transferred to cultures whose performative practices rely much more on visual 
and auditory (musical) effects? What is the profile of appropriated and of rejected material, focusing on those cases in which processes of appropriation are relatively free, in the sense of not being imposed in an authoritarian way? Does the "import" of western cultural material change the local notion of theater (if there is any)? Is there any "reverse circulation" taking place? And if reverse processes are to be observed, are they part of larger floating processes, including additional cultural material, from the periphery to the European centers? ${ }^{414}$

Indian drama of the eighteenth and nineteenth centuries offers a great deal of insight into the questions outlined above. ${ }^{415}$ The "transfer" of European drama, including translations, to colonial India took place as early as around the year 1800. 416 Some five decades later, the first (modern) plays written in Indian vernaculars emerge. I will concentrate my brief remarks on two early plays considered by specialists to be the most important ones and which, in addition, allow for the consideration of two different variants of working with "exogenous" material extracted from the net.

The play Sermista $(1858 / 1859)^{417}$ by Madhusudan Dutta-which, by coincidence, appeared in the very same year as the second play I will discuss, Nil Darpan-may be characterized as based on the "importation" of the formal structure of European, in particular Shakespearean drama (five acts, blank verse). However, the content associated with this new form is autochthonous; it consists of a mythological narrative derived from the tradition of the Sanskrit epics. The configuration of the narrative is not alien to Western literature; it is based on a love triangle. But the fact that the triangle involves one male and two females, as well as the fairytale-like ending "attached" to the conflict, are features which are rather uncommon in the Occident. Thus, what may be observed in the case of Sermista is the assembly of a dramatic work by means of the fusion of content and a formal pattern that had constituted distinct items in the universal cultural net up to that point in time. To understand the significance of the "extraction" of this formal pattern, it is crucial to keep in mind that there was no drama in the modern sense of the term within the Indian culture of historical, that is, post-mythical times. ${ }^{418}$ There were small groups

414 All related questions are dealt with in detail by Gautam Chakrabarti in his book Familiarising the Exotic: Introducing European Drama in Early Modern India.

415 See Chakrabarti, Familiarising the Exotic.

416 I shall come back to this fascinating process in a later section of this chapter (pp. 217-220).

417 The Bengali version was written in 1858, while the date of 1859 refers to the translation into English.

418 This statement needs to be qualified, but the details are not pertinent to the above discussion (see n. 423). 
of itinerant actors who presented a variant of performative practices one might call "street theater", performances close to what one would call farces in the West, that is, short scenes, mainly comic, partly obscene, and based upon personages derived from the fund of popular culture.

In the case of the second text I should like to highlight, Nil Darpan or The Indigo Planting Mirror (1858/1859) by Dinabandhu Mitra, it is, in addition to the formal pattern, the content, or rather the ideological narrative to which the content refers, that is imported from Europe. ${ }^{419}$ Both features are then assimilated to an Indian setting. The story presented consists in a narrative well known from The Communist Manifesto (1848) and to be found later on in various fictionalized versions in Europe, for example in Zola's Germinal (1885): it deals with the shameless exploitation of the working poor by the bourgeoisie, the support of the exploiters by both the state and religious institutions, and finally the revolt of the exploited, which is thus presented as morally justified. The foundational parameters of a society committed to a rigid hierarchy, most pithily expressed in the caste system, were thus problematized from the standpoint of egalitarianism, which was indeed an exotic feature in nineteenth-century India, but which then became, no less than in the West, the dominant discourse on the organization of society.-It is essential to note that the above-characterized "import" of a formal structure, subsequently assimilated to a traditional story, opened Indian society up for the much more comprehensive import of a form-plus-content structure which was adapted to local social reality and thus able to produce, so to speak, an extra-dramatic social discourse which functioned as an instrument for propagating the concept of equality. ${ }^{420}$

With regard to the author of Sermista in particular, there are a few remarks to be made which are pertinent to the theoretical discussions undertaken in this book. Dutta was educated in British colonial institutions. As an adult, he converted to Christianity, took the additional first name of "Michael", and married an English woman. After divorcing her, he married a French woman. He wrote his works in Bengali as well as in English, translating the texts himself. He is the first great canonical author of modern Bengali literature. Because of his adoption of a British lifestyle, he had issues with his family, but the local ruling

419 The European form of drama had already been imported to India, as I shall explain in the following pages, by a Russian adventurer named Lebedev.

420 Taking the production dates of the two dramas into consideration, one must note that Nil Darpan, and even more so the ideology contained in it, began deploying its full impact only in the decades following the first performance. 
class of nabobs and princes generously supported his work. He stands as a paradigmatic cultural mediator.

Dutta left behind an abundant correspondence in which he addresses the question of his self-image. There is practically no canonical author from the Western and Southern European literary traditions whom he does not mention as a model for his own works. It is striking, however, that two names appear more frequently than the rest: Virgil and Milton. If one keeps in mind that the Aeneid (29-19 $\mathrm{BCE}$ ) is modeled on a Greek text, and that it is only in retrospect that the "classical pagan tradition" appears to be homogeneous-in fact, prior to the relevant processes of transculturation, Roman culture was as far away from Greek culture as the traditions of the Black Sea region-and if one keeps in mind that Paradise Lost (1667) is about a religious patrimony deeply anchored in England at that time, but which did not have its "roots" in that part of the world, Dutta's selfpresentation as an Indian Virgil or Milton appears perfectly transparent. The concept underlying such a "self-fashioning" is apparently one of transculturation and its highly fruitful results. The idea is all but new. It is famously expressed, setting aside its implied presence in the Aeneid, as early as in the twelfth century, in Chrétien de Troyes's prologue to his romance Cligès. ${ }^{421}$ If the clergie, that is, study and culture, has traveled from Jerusalem to Athens, then to Rome, and from there to Paris, it is in no way astonishing that it should continue to migrate-in this case, first to London, then to Calcutta; and it can be expected that it will probably not stop there. In terms of cultural theory, one may rightly conceive of Dutta as a new Chrétien de Troyes. ${ }^{422}$

It is not only the modern Indian drama proper, which emerges in the middle of the nineteenth century, but also its prehistory that is quite instructive with regard to the overall problems addressed in this study. At the time in question, the material substratum of circulatory movements within the cultural net is, as argued above, mainly constituted by traveling humans. In a later age, when printing becomes widespread, and even more so in the present-day era of electronic communication, the primary material substratum of circulation changes and the speed of circulation increases in a most spectacular way; but in the period under scrutiny, human agents are typically the media of transportation.

421 "Ce nos ont nostre livre apris, / Que Grece ot de la chevalerie / Le premier los et de clergie. / Puis vint chevalerie a Rome / Et de la clergie la some, / Qui or est an France venue.” // "Our books have informed us that the preeminence in chivalry and learning once belonged to Greece. Then chivalry passed to Rome, together with that highest learning which now has come to France" (vv. 30-35; W. W. Comfort [tr.], online edition, "heroofcamelot.com").

422 In order to avoid misunderstanding, I would like to stress that I do not claim a similar rank for his literary works. 
When it comes to specific forms of circulation, I have mainly considered in detail two different human modes of activity contributing to the circulatory processes. These two modes have in common that they are intentional and thus prearranged: the circulation does not just happen, but is planned, organized, and implemented. The first of these two patterns might be called "cultural exportation" and is based on cultural-ideological expansionism. One well-known example from the early modern age is the export of European Christian didactical drama to regions as different as Latin America and Japan, which occurred in the seventeenth century; the media of transportation in this case were mainly Jesuit missionaries. Another such example, from a period beginning about 150 years later, would be the exportation not only of drama, but of the entirety of French civilisation, orchestrated by the modern French state in the frame of nineteenthcentury colonialism. The ideological basis shared by these mechanisms of export is typical of all such propagative circulatory activities within the net, including in the present: it is universalism, the (religious, secular, or hybrid) assumption that all members of the species are in essence the same and are thus capable of sharing, and in fact obliged to share, basic cultural patterns and features.

The second variant of such conscious and prearranged circulation may be labeled "cultural importation". The examples discussed above were the French importation of Italian culture in the Renaissance and the importation of French and German culture into Russia in the Age of Enlightenment. The vehicle of circulation is in most cases constituted by dynastic bonds-by princesses married off to monarchs of the "importing" countries-and the motivational basis might vary from quite down-to-earth and private aspects (making the new wife happy by allowing her to indulge in cultural events familiar to her) to political reasons: the recognition of the "receiving" monarchy that the spouse's culture is more developed than its own and that not only the dynasty, but the state and the society in their entirety might profit from the "transfusion" initiated by exogamy.

One should, however, not lose sight of the fact that a good deal of cultural circulation follows more fortuitous and contingent paths than the two conscious and prearranged patterns just summarized, even in cases where it is not a parasitic phenomenon, that is, a by-product of economic or military activities. Gautam Chakrabarti has studied the entire temporal range of the circulation of European drama to colonial India, its hybridization with the local production in its elite (Sanskrit) as well as in its popular forms, ${ }^{423}$ and the return

423 The plays in Sanskrit (a language accessible in modern times only to Brahmins) as theorized in the Natyashastra tract and still extant in modernity-the most famous being Kalidasa's play titled Shakuntala, translated into English by Sir William Jones in 1789 and later enthusiastically praised by Goethe-had no longer been performed on the Indian stage since times im- 
flow of modern Indian theater to Europe, which mainly occurred in the second half of the twentieth century. From a nonspecialist's perspective, one of the most striking points highlighted in his book is the fact that, contrary to all possible expectations, the British colonizers were not the agents responsible for initiating this process. Chakrabarti argues that the British, at least up to the second half of the nineteenth century, when Queen Victoria adopted the title of Empress of India and started considering the subcontinent as an integral part of her realm, did not have the ambition to culturally colonize India. The reasons for this difference from Spanish, French, and, later on, American models may be multifarious and need not be discussed here in detail. One point to be taken into consideration is certainly the fact that the colonization of India was not a state activity at its outset. The East India Company was a private enterprise whose sole intention was to make a profit. For decades, if not centuries, the British considered India as a territory of exploitation, not of cultural propagation and ideological assimilation.

This said, one must account for the fact that European dramas, starting with pieces by Molière (L'amour médecin [1665]) and Richard P. Jodrell (The Disguise [1787]), were translated into Bengali with the intention of performing them on a stage in Calcutta, in India's first-ever modern theater, as early as at the end of the eighteenth century, that is, roughly half a century before the abovecharacterized emergence of "local" dramatic production. ${ }^{424}$ The agent of this circulatory process was, astonishingly, not a British colonizer or cultural agent, but a Russian, Gerasim Stepanovich Lebedev (1749-1817). I will not go into the details of his remarkable biography, but will leave it at saying that he was born in a provincial town of his country of origin, became a musician, was taken to St. Petersburg as a young adult, came into contact with high-ranking aristocrats, traveled in their company to Vienna, Paris, and the rest of Western Eu-

memorial. Amongst the educated belonging to the highest caste, they continued to be read and thus were part of the cultural consciousness of those who, in some way, might be seen as the intellectual class of India.

424 As early as on November 27, 1795, Lebedev staged the first-ever "modern" play on the Indian subcontinent; it was written in the Bengali language and based on The Disguise (it seems that Lebedev forsook the project of staging the comedy by Molière). The Disguise in Bengali was more of an adaptation than a faithful translation, so this fact does not jar with the above remarks about the way in which Western theatrical culture entered modern India. In addition, it is controversial whether the translation was Lebedev's own or whether it was partly or even exclusively produced by Lebedev's teacher of Bengali, Goloknath Das. At any rate, the initiative was Lebedev's, and this is the only point that counts in the present context. 
rope, and then, by chance, happened to travel to India, ${ }^{425}$ where he first sought to survive as a musician. He was not very successful in that line of business; in order to improve his economic situation, he shifted his focus to theatrical productions and established the above-mentioned stage.

Lebedev took an authentic interest in Indian culture. He learned Sanskrit and Bengali and discussed his translations of European plays with local scholars. In a way, he was one of the first Europeans to consider traditional Indian culture with respect and admiration. He was a precursor of those who, in the age of Romanticism, would cast India as the cradle of European culture (e.g., Friedrich Schlegel). What is less known, and has first been brought to light by Chakrabarti's book, which takes Lebedev's private correspondences into consideration, is the political motivation behind this attitude. Basically, Lebedev was a Russian nationalist. From his perspective, there is no question that it Russia, not Britain, which is predestined to rule over India; let me recall that, up to the end of the Soviet Union, and possibly into the present, it has been a Russian ambition to control the Indian subcontinent, not least in order to become a maritime power of global dimensions, which was and is impossible as long as its influence is confined to its traditional territories, which contain no ice-free ports. ${ }^{426}$ In his letters, Lebedev gives expression to the idea that the superficial, materialistically oriented, capitalist colonial regime established by the British is not what India needs; what is required, according to him, is rather a cultural colonization, based, however, on the careful acquisition of India's cultural patrimony.

There is one minor and one major point to be derived from the astonishing scenario of a Russian acting as the agent of the circulation of Western European dramatic culture to British India. Had the British known about Lebedev's political convictions, they most probably would have flatly expelled him from their colony. Lebedev's interactions with the British authorities were not free from strife; but ultimately, the British let him do what he did. This constellation reconfirms a speculation already advanced above: literary items float more freely than explicitly ideological items do (political ideas, religions); and, as I should like to add, than material goods do, at least in the industrial age. With

425 There are some obscure points in Lebedev's biography. It may be that he traveled to India driven by exoticism, the longing for adventures, etc. But it may also be the case that he adopted from his aristocratic masters the habit of gambling and had to leave the Old World in order to avoid being imprisoned because of debts.

$\mathbf{4 2 6}$-or ports that are separated from the ocean by straits easily controllable by competing maritime forces (Crimea, the Dardanelles). 
regard to ideology and industrial commodities, modern states have the tendency to make systematic use of their apparatuses of control in order to strictly contain the "intake" of exotic material. Culture in the narrower sense of literature and other forms of art is considered from Plato through Augustine, Aquinas, Kant, and Hegel as something that deserves a certain amount of attention, but does not count among the "truly important" things, such as religion, knowledge, or morals. It is the fact that culture in this narrower sense is ultimately considered as adiaphora ${ }^{427}$ that allows for processes of circulation which at first sight no one would expect to be possible.

But the more important point to be drawn from the Indian scenario is this one: Lebedev is a maverick figure, an adventurer, not a scholar or someone who set out on his journey as a conscious cultural missionary. He is a somewhat eccentric figure. In this regard, he is not an isolated phenomenon when it comes to cultural transfer. As has been noted already, it was not intentionally, but by chance that he traveled to India-as it occurred by chance that another such eccentric figure, Christopher Columbus, traveled not to India, where he intended to go, but to a place which was later to become America. The consequences of this latter eccentric's activities in the field of culture were much more significant than Lebedev's. Columbus's voyage marks the inception of the more or less violent reconnection of the continents discovered by him to the universal cultural net, the ensuing westernization of South America, and, later on, of North America; and it is highly probable that it was the successful cultural colonization of these two subcontinents which paved the way for the westernization of the entire globe, a longue durée movement of human history which is still going on today.

How would India and the rest of the world look today had people like Lebedev and Columbus been a little bit more "cautious" and "reasonable" than they actually were? And what would the world look like had they fallen prey to a banal accident, say, a shipwreck, before they arrived, respectively, on the shores of America and of India? In the age of modernity proper, the circulation of cultural material seems to occur in most cases according to bureaucratized patterns, driven by state interests, ideologies, or the systematic search for profit on the part of private companies. Lebedev and Columbus seem to be representative of a pattern that may have been dominant in the entire premodern age, that is to say, during most of the species' history so far. Those of our first

427 From the standpoint of all of the "official" philosophers named above, the truly dangerous discourses are the skeptical or cynical philosophies which deny the possibility of knowledge or the mandatory status of (specific) morals. 
ancestors who dared to leave the East African savannah and migrate northward; the slaves leaving Egypt led by a fearless man later known as Moses; the Greeks travelling to Asia Minor; Alexander the Great conquering territories as distant as Northern India, etc., etc.-all these people were eccentrics, adventurers who might easily have failed. And many of them did fail, leaving no traces precisely for this reason. Processes of cultural exchange are subject, during the greater part of human history, to the non-existent laws of contingency. It is only interpretative frames like religions or philosophies of history which try to impose a logic upon what is basically a-systematic, erratic, and fortuitous.

2.-It may be that it is the case of the emergence of Russian drama that is best suited for the discussion of a point that has not yet been extensively addressed, namely, the interaction of multiple, highly diverse factors when it comes to the withdrawal of material circulating in the net and to its reconfiguration into novel entities, new (“original”) works.

The (hi)story of Russian drama as expounded in Kirill Ospovat's book ${ }^{428}$ may perhaps be systematized as follows: In keeping with the position of certain church fathers, all forms of theater were forbidden up to the late seventeenth century. It cannot be systematically ruled out that there were improvised sketches performed as street theater, that is, analogues to what are called farces in Western Europe. The vastness of the territory, its relative underpopulation, and the complete lack of written documentation pertaining to regions other than the urban centers (which were under the strict control of the ecclesiastical authorities, for which reason there was certainly no theater whatsoever in these places) make definitive statements regarding the point in question problematic. Religious theater in its Western forms-mystery and morality plays-was avoided as a consequence of the isolationist perspective adopted by the Russian Orthodox Church; any similarity with Catholicism raised the suspicion of heresy. But it may be that it was precisely this constellation that facilitated the emergence of a sort of liturgical drama in Russia starting in the sixteenth century. In Catholic territories, beginning in the twelfth century, drama as part of the liturgy had been abandoned in favor of a religious drama proper that was performed independently of the Mass. Consequently, the pattern of liturgical performance as such could be considered as no longer "contagious". Be that as it may, there is only one documented example extant of the Russian variant of liturgical drama; it is known as the "Act of the Furnace" (Peshchnoe deistvo). The play stages the Old Testa-

428 Terror and Pity. 
ment story of Daniel; it was regularly performed in cathedrals across the country before Christmas. ${ }^{429}$

Things began to change in the late seventeenth century, once Russia had reconquered Orthodox territories from Poland, where the Orthodox faith had been amalgamated with "Catholic" cultural practices such as public schools and school theater. But the main conditioning factor was the establishment of a courtly society, which occurred relatively late on Russian territory. Peter the Great (who ruled from 1682 to 1721) and the two empresses Elizabeth (17411762) and Catherine (1762-1796) were the monarchs who brought the Tsarist court to a level of cultivation comparable to the courts of Central and Western Europe. As for the latter of the two empresses, the reasons behind this development are rather obvious. When she "migrated" eastward from her country of origin, she made use of her rapidly attained position as absolute ruler to import, as it were, the cultural practices familiar to her. As French language and culture were dominant at contemporary courts located on German territories, it was mainly the model of French tragedy, but also of pastoral play, including the new genre of opera, which made their way into eighteenth-century Russia.

The first phase of this cultural westernization of Eastern Europe set in, however, as early as during the reign of Elizabeth. ${ }^{430}$ Many of the first tragedies in Russian, written by Aleksandr P. Sumarokov, were not direct imitations of pieces by Racine or Voltaire. This said, the influence of the great French authors is evident; but in order to adequately describe Sumarokov's dramas, one must take another factor into consideration: in this book's terminology, the aspect of "local demand", which differed in profile, at least in part, from the case of France. French authors of the age carefully avoided writing pieces dealing with their own, that is, French history. If they thematized historical stories, they usually had recourse to Greece and Rome, in some cases to Spain (Corneille's Le Cid [1636]), and at times even to “exotic" material (Voltaire’s Zaïre [1732]); ${ }^{431}$ but they did not adapt the great tradition of classical Greek historical tragedy to their own national framework. The current explanation for this attitude of avoiding plots pertaining to French history seems to be convincing: in a coun-

429 Sergei M. Eisenstein included one such performance in his famous film Ivan the Terrible (1944/58).

430 Elizabeth was an illegitimate, then legitimized daughter of Peter the Great; that is, she was born and raised in the country. Some of her teachers did come from abroad, but her cultural background was of a different profile than that of her successor, Catherine II.

431 Parts of this latter play were translated into Russian by Sumarokov. 
try whose recent past had been characterized by factionalism-both political and religious-and where open civil war had only been avoided by events like the Saint Bartholomew's Day massacre, the regained peace, whether based on reconciliation or on repression, could well have been disturbed by bringing plots drawn from French history to the stage.

In Russia, things were different. There was no lack of internal conflict; several coups d'état had taken place, resulting in the permanent menace of civil war. However, there was also another factor to take into consideration: a demand that was even stronger than the one for stories fostering internal peace. This demand was for what is later known as "nation-building", in this case the constitution of something like a Russian identity with the Tsarist court at its center. Identity, however, is always based on historical narratives ("we are the ones whose ancestors fought this and that fight, who suffered this and that hardship, but who succeeded in recovering from the sufferings and are now heading towards a glorious future"). Consequently, some of Sumarokov's tragedies deal with the history of what became "Russia" only in the sixteenth and seventeenth centuries.

The legitimization of this at first sight quite bold reshaping of the French material drawn from the net made use of another "package" of cultural material available, namely, the text on which the entire post-fifth-century-BCE history of the genre is based: Aristotle's Poetics. As is well known, but was neglected in the French discussion, Aristotle differentiates between drama (tragedy) on the one hand and history on the other, but goes on to argue that plots for tragedies may be invented by the author, taken from the familiar fund of mythology, or drawn from history. ${ }^{432}$ What might at first sight seem inconsistent is solidly anchored in the Aristotelian conception of the genre. If it is the task of tragedy to convey something "general" about the world, certain historical plots may be a very apt source; if history is largely the domain of the contingent and the fortuitous, this does not mean that every segment of it defies causal explanation. "Historical" drama is, to put it succinctly, one of the options an author is free to choose if he intends to conceive a well-wrought tragedy. This aspect of the Aristotelian argument was, as has been said, partially relegated to the background in the French discussion, at least as far as the country's own history was concerned; it was detached from the argument presented by the Stagirite.

432 Poetics, chap. 9. 
However, the aspect was a prominent one in the German discussion on tragedy and serious drama. ${ }^{433}$ The reasons for the revival and emphasis of what had been neglected by the French are evident: Germany, a not yet existent nation struggling for its cultural autonomy vis-à-vis its firmly established Western neighbor, was keen to demonstrate to the "world"-that is, to the educated classes of Europe-that it had a meaningful contribution to make to discussions of common European interest; or, to put it somewhat more bluntly: German theoreticians of the time had the ambition to prove the French wrong, to accuse them of having read Aristotle only superficially or even of having distorted him.-A strong "local" demand for cultural patterns of nation-building, the absorption of French tragic material (mainly Racine, but also Corneille and Voltaire), and the reception of the "anti-French" reading of the Poetics as developed in contemporary Germany seem to have formed the basis of pieces like Khorev (1747/1749), the first Russian neo-classical drama, or of Dimitrii Samozvanets (1771). Let me stress that I mean what I say: these items constituted the basis for what was then achieved by the author Sumarokov. One can legitimately doubt that any other author would have been able to create such masterpieces of traged $y^{434}$ out of these diverse impulses taken from the net. But creatio ex nihilo, the godlike work allegedly performed by writers and artists according to the enthusiastic art theories emerging as simplifications of Kant's Critique of Judgment and which we subsume under the label of Romanticism-this seems to be an illusion when human affairs are concerned.

3.-Limitation is a feature of all human efforts. Sub-projects were conducted by the DramaNet research group treating what has been labeled in recent years littératures mineures (Slovenia, Tyrol); but for various reasons, it was not possible to undertake a more detailed analysis of the situation in medium-sized European cultures such as the Netherlands, Denmark, and Sweden. As an inevitably insufficient substitute for this missing part, which might be supplemented by further research in the future, I would like to improvise some remarks on the Netherlands and its theatrical culture in early modern times.

The most outstanding author in this regard is Joost van den Vondel (1587-1679). Born in Cologne of parents who had left Antwerp because of their adherence

433 See Johann Christoph Gottsched, Noethiger Vorrath zur Geschichte der deutschen Dramatischen Dichtkunst (1765); Gotthold Ephraim Lessing assigned the subtitle "Historiendrama aus der Zeit des Dritten Kreuzzugs" to his famous play Nathan der Weise (1779).

434 The literary quality of Sumarokov's plays is controversial. From my historicizing perspective, I read them with delight; but I will leave it to the specialists to assess them in terms of aesthetics. 
to Protestantism, ${ }^{435}$ he relocated to the Netherlands when he was an adult, later converting to Catholicism. Vondel is heavily influenced-in this specific case, directly and consciously-by the dramatic work of Shakespeare, as Dutch culture in general, both in its everyday as well as in its refined strata, has throughout the centuries mainly been modeled on English patterns. ${ }^{436}$ Many of Vondel's plays are "emulations" of Shakespearean plays, in the sense of the term current in classical cultural and poetic theory: imitations with the intention of surpassing the model.

Reading Vondel's plays, one gets the impression that the author interpreted "better" mainly as "even more violent and bloody". Shakespeare's plays are already paradigmatically cruel. In the final scenes, there are frequently more corpses to be seen on stage than living people. But all of this is "nothing" when compared to Vondel's plays. Who would be able nowadays to conceive an episode consisting of several dozens of catholic nuns stabbed by the "heretics" and then lying on the ground quite like a "wreath of roses white and red", as the dramatist did in his most popular play, Gijsbrecht van Amstel (1637);437 or who would indulge in the "pleasure" of having a decapitation recounted in detail twice, as in Maria Stuart of gemartelde majesteit (1646)?

Considering the scenario as a whole, one has to add that the contemporary dramatic production of the Netherlands' eastern neighbor, Germany, displays

\footnotetext{
435 Like many other Flemish-Dutch cities, Antwerp had embraced Protestantism; the Spaniards who ruled over this part of North-Western Europe at that time had more or less violently reestablished Catholicism as the only legitimate Christian cult. Cologne-not very far from Antwerp-, where many Flemish Protestants sought refuge, was mainly Catholic, but parts of the population had become Protestant. The period at stake is situated before the re-establishment of Catholicism as the exclusive denomination in that part of the Rhineland.

436 In addition, there is an important, but in comparison minor, influence of German as well as French models, the impact of the latter being limited to the upper strata of the population: the nobility, the wealthy bourgeoisie, and the intellectuals. The reason for the general preference of English over German patterns is obviously the territorial as well as linguistic affinity to Germany, the resulting fear of absorption, and the attempt of the nation to distance itself from the-perhaps all too-big neighbor by building close links with another big country which had stopped nurturing the wish to govern the continent or parts of it at the end of the Hundred Years' War.

437 See vv. 1435 ff.; the most recent publication characterizing Vondel's works is Nigel Smith's "The Politics of Tragedy in the Dutch Republic: Joachim Oudaen's Martyr Drama in Context", in: Gvozdeva et al. (eds.), Dramatic Experience, pp. 220-249.-I should add to the above remarks on the way atrocities were presented in plays by Vondel that there were prominent Dutch playwrights at the time, e.g. Jan Vos, who did not refrain from having events such as beheadings represented on stage.
} 
quite similar tendencies. Within a traditional frame of stereotypes of national character, one would be tempted to explain the bloodiness of many of Gryphius's, Lohenstein's, and Vondel's plays by referring to a Germanic or Teutonic penchant for transgressing all moral boundaries when it comes to violent conflict. But even though the Netherlands were not always as peaceful and politically correct as they have been in recent decades, it would be quite problematic to explain the amount of atrocities in Vondel's plays by referring to a supposed propensity of "the Dutch" ${ }^{438}$ to slaughter their enemies in a particularly cruel manner.

My tentative explanation would be quite another one. In contrast to Spain and France, but similarly to Britain, we are dealing in the cases of Germany and the Netherlands with religiously divided nations. The difference with regard to Britain and Germany consists in the fact that the Dutch religious divide is a rather open one. In Britain, political as well as cultural power was in the hands of the Anglicans. In Germany, there were kingdoms and principalities which were either (entirely) Protestant or (entirely) Catholic. In the Netherlands, the ruler was Protestant, since the country gained its independence in a guerilla revolt against a Catholic “oppressor”, Spain. But the cultural, intellectual, and economic elite, as well as the populace, were more or less equally divided into the two major Christian denominations. The plays I mentioned originate from the post-Westphalian period, or from a period immediately preceding the peace treaty, that is, from a time when many European nations had decided, after thirty years of bloody war without a victor-half of the population had lost their livesto no longer make questions of religious denomination a reason for killing each other. The emotional energies unleashed by thirty and more years of terrible atrocities, however, were still virulent. How to tame these aggressive affects?

As already partly suggested above, my speculative explanation would start from Freud's theory of literature as imaginary wish fulfillment, as a compensatory realm where we can get, thanks to our imagination, what reality is unable to give us. ${ }^{439}$ The staged atrocities may have helped to catharticize the "real" aggression, still virulent, of spectators towards members of other denominations, and thus might have been a way to help establish inner peace. In this way, dramas such as Vondel's might be considered paradigms of what visual mass culture is, according to me: an instrument for producing social cohesion. The mimicked cruelties may have served as a palliative against the "suffering"

438 As said, Vondel was born in Cologne, Germany, while his parents were from Antwerp. But the point in question is not the author and his ethnic or cultural belonging; it is the audience who avidly received the above-characterized, at times incredibly bloody plays.

439 See, once again, the reference given in n. 56. 
(the frustration) originating from the state-imposed reconversion of wild beasts on two feet into more or less civilized human beings. 440

4.-There are extremely intricate questions implied when it comes to discussing the point, mentioned on various occasions, of the different degrees of organization of the material circulating in the net. There are elementary units ("functions" in the sense of Vladimir Propp); there are certain emblematic figures (like the Hanswurst in Austrian popular drama, both urban and "rural", whose AngloSaxon analogue would be figures like Pickelhering ${ }^{441}$ ); there are standardized assemblages of elementary units (certain joke-structures in comedies; anagnorisis and peripeteia in tragedies); there are genres; and finally there are entire stories which not only circulate in the net-according to my assumptions, all stories ever written or devised do this-but which are also extracted and then reworked as entire stories; the Griselda story is one such case of the highest level of organization of a given item floating in the net.

The study conducted by Pauline Beaucé as part of the DramaNet project ${ }^{442}$ opens up interesting considerations pertaining to an intermediate level of rather high organization that is more strictly organized than a specific generic pattern, but nevertheless does not attain the level of detailed organization typical of a particular story and its variants. The difficulty of finding a correct term for such phenomena becomes evident in scholarship in which they tend to be labeled-unsatisfactorily-“traditions". In line with Beaucé's findings, I will be addressing the pastoral as one prominent example of such a tradition. ${ }^{443}$

When it comes to defining the (postclassical) pastoral, which seems to have originated as narrative, but is drawn upon in early modern times for drama as well-Guarini's Pastor fido (1580/1584) being the most prominent example-

440 From a Freudian standpoint, the dramas mentioned would achieve this compensatory function with regard both to Catholic and to Protestant audiences. The scene of the stabbing of the nuns would allow a Catholic spectator to fantasmatically unleash his aggressions against the heretics who are capable of perpetrating such unheard-of atrocities. A protestant spectator, on the contrary, would have indulged in his hatred against nuns and monks as the most powerful earthly agents of the Devil, who are being rightly punished for their evildoing. 441 See M. A. Katritzky, "Stefanelo Botarga and Pickelhering: Fishy Italian and English Stage Clowns in Spain and Germany”, in: Küpper et al. (eds.), Theatre Cultures within Globalising Empires.

442 Parodies d'opéra au siècle des Lumières (chap. 5, "Parodie, ballet et pastorale: l'union des genres"); see also "Pour une réévaluation des formes mineures dans l'historiographie du théâtre des Lumières: le cas forain”, Horizons/Théâtre vol. 5/2014, pp. 59-73.

443 Another example not discussed here directly, but which could likely be captured along similar lines as the following, would be the Hellenistic novel, of which Heliodorus' Aethiopica (third or fourth century CE) is the best-known extant textual instance. 
the main features are easy to enumerate: the plots deal with shepherds and shepherdesses, but not "real" ones, not hard-working rural people whose bodies have become gnarled and buckled before their time as a result of backbreaking labor. Readers are presented, rather, with idealized shepherds who do not have to work in order to live, but who are eternally young, beautiful, and healthy. The setting is rustic, but without the inconveniences of an authentically rural environment; the scenery is pleasant, the weather serene. The plot revolves around love. There is no way to tell a story about love without dealing with the delicate problem of the instability of feelings and relationships, for if there is stability-as in fairytale endings-there is nothing more to narrate. But the pastoral invented what one could label a "non-traumatic" way of staging emotional instability. If, as frequently occurs, a certain Sylvestrus is forsaken by an unfaithful Phyllis who then continues her joyful life with a certain Corydon, Sylvestrus might sing a moderately sad song in which he laments the emotional instability of the female sex in general; but the beauty of his voice might then attract a certain Daphne who is immediately prepared to make him forget Phyllis forever.-It is evident that the scheme is episodic; it allows for a potentially endless concatenation of specific stories, and for easy variation just by changing the personages' names, or by slightly changing the features of the rustic setting (from riverbanks to mountains, etc.).

This pagan sort of paradise was devised in classical times. Theocritus, Virgil, and Ovid are the most important authors to thematize it. It was "reborn" in the age that bears precisely this name, then attained an amazing degree of popularity in all European literatures from the late sixteenth century onward. It ceased to be in such high demand in the nineteenth century, and in the twentieth became one of those items circulating in the net without being extracted; I should like to add that this is not the case for a comparable popular genre, the Hellenistic novel, which to this day constitutes the basic framework of most fantasy fiction. However, the pastoral tradition may be experiencing a powerful afterlife outside of Europe; very many Bollywood films could be considered "Indianized" variants of the pattern.

The questions provoked by the "tradition" mentioned within this book's framework concern two different points. Firstly, the (extremely) high stability of the pastoral's basic features contravenes the basic categories developed at the beginning of the twentieth century by the Russian formalists for the express purpose of differentiating the literature of high culture from popular fiction. According to the formalists-who are in the final analysis Kantians-innovation, originality is the main criterion for judging whether works are worthy of being called "literature." It seems that this is not always the case.-The second theoretically relevant point raised by the constellation outlined is the question of 
why the power of the pattern seems to have waned, why it has ceased (in the West) to be extracted from the net, at least for the time being.

The explanation proposed here as to the first question refers to a category made use of quite frequently above, namely, that of demand, which might be further specified by the following remark: when demand is high, the fact that there is not much innovation to be found in different instances of the genre or subgenre in question seems not to bother readers, not even sophisticated ones. ${ }^{444}$ Regarding the second point to be discussed, one might speculate that certain demands are fulfilled by certain cultural or literary patterns in certain places and at certain times, but not everywhere and not permanently; the capability of cultural artifacts to satisfy a given demand may be liable to changing circumstances.

The concept of demand I am referring to is inspired, once again, by Freud's radically anti-Kantian short essay on the function of reading literary texts (or of viewing fiction) entitled Der Dichter und das Phantasieren. Based on his main insight that civilization is grounded on the repression of drives, Freud theorizes fiction as a compensatory register. Literary texts allow us to temporarily indulge in the illusion of living in a world where we are not subject to the manifold strictures regulating our "real" lives. They allow for imaginary wish fulfillment. Since our wishes are simple and constant, and since the apparatus of repression called civilization is stable as well, it is not astonishing, from a Freudian perspective, that there is much stability to be found in the history of fiction; and since the psychic apparatus is basically the same for all members of the species, it is no more astonishing that there is not much difference, as to

444 I should like to add that this remark is also pertinent with respect to a problem I do not discuss in this book: why is it that even in post-Romantic times, that is, in periods of artistic production and reception obsessed with the criterion of "novelty" or "innovation", there is a very intense ongoing reception of works which are not novel at all to the audience? As to the performing arts (theater, music), every performance clearly introduces new accentuations; and even in the case of the arts which produce materially immutable works (texts, paintings), one can reasonably argue that every new reception on the part of a specific recipient will lead her or him to a "new" interpretation of the work in question. But even enthusiasts of reader-response theory (Rezeptionsästhetik) would hardly deny that there is a difference in terms of "novelty" between a renewed reading of, say, Le Père Goriot and a first reading of L'Éducation sentimentale. My speculation would be, succinctly put, that there is a (small) number of works for whose reception there is a sustained demand although they are already familiar to every cultured reader. As the above paragraph may elucidate, this statement does not mean that there is a (Platonic) timeless dignity of certain works. As we may observe in the present age, texts which were once believed to be beyond the vicissitudes of time, for example the Iliad, may lose their popularity. But, as I should like to say in order to distance my position, once again, from that of the Russian formalists (whom I otherwise highly esteem), "demand" may outweigh "automatization". 
basic and abstract patterns, between the fictions devised by different cultures. In the case of the pastoral, this potential of imaginary wish fulfillment is not difficult to describe: pastoral novels, operas, and poems devise a world without the constraints of hard labor, without the strictures of civilized life, without the intemperate vicissitudes of "stepmother nature", without the bonds and burdens of family life, and without the traumas inflicted upon humans by lasting emotional and sexual frustration.

One possible answer to the question of why the pattern is no longer extracted from the net in twentieth-century Western literatures and of why it goes on being attractive in countries like India might not be very hard to imagine: the processes of industrialization and liberalization have freed Western people at least partly from those constraints their ancestors in early modernity experienced as so oppressive that they did not see any other way to cope with them than through compensatory fantasizing.-But there is another insight to be gained from a careful scrutiny of the history of the pastoral. In the age of the French Enlightenment, the tradition underwent a functional change or re-accentuation, whose best-known textual products are Rousseau's Nouvelle Héloïse (1761) and (perhaps even more) his Du contrat social (1762). I shall not go into details here; suffice it to say that the genre became mimeticized and underwent a functional transformation from fantasmatic to utopian, or rather uchronian. ${ }^{445}$ The Rousseauian ideal of a rustic society whose members are free from hard labor, and where societal and emotional problems are tempered by benevolent circumstances as well as by the omnipresence of internalized raison, is nothing other than a rewriting of the pastoral with the aim of putting it into "real-world" practice.-It would not be misled to link Marx's praise of the future communist society as formulated in the Manifesto to this tradition of a mimeticized and "uchronized" pastoral.

Beginning at the end of the eighteenth century, the literary pastoral was recast as a political program. It may be that it was this re-functionalization alone which caused its rather complete loss of attractiveness as literary material from

445 This term, generated in analogy to the one created by Thomas More, was first introduced by Charles Renouvier in his novel Uchronie (L'Utopie dans l'histoire), esquisse historique apocryphe du développement de la civilisation européenne tel qu'il n'a pas été, tel qu'il aurait pu être (1857/1876); it designates literary models of an alternative "reality" that do not have recourse to a place (topos) unknown, but rather to a time or period (chronos) unknown, in most cases, to the future. - My above characterization of Rousseau's novel may not convince every reader of this book; it implies an interpretation of the heroine's premature death. According to my view, the end of the text does not convey that passion and reason are irreconcilable, but, rather, that it is necessary to "implement" even much more reason in the sphere of human relations than is the case in the novel. 
the middle of the nineteenth century onward. But it may also be that the insight, fully realized only in the last third of the twentieth century, that the Rousseauian or Marxian conception of a pastoral put into practice will never be able to come true, compromised the pastoral pattern as a mode of fantasizing. Fantasies for which one must strictly exclude the possibility of their realization do not have a compensatory dimension.

5.-Finally, I would like to pick just one example in order to illustrate the astonishing degree to which processes of circulation of cultural material may lead to innovations completely unintended by those who first produced a constellation that was then extracted and reworked under different circumstances. The point to be discussed is apt to problematize all concepts of an (at least intraliterary) teleology, unless one is willing to make the assumption that human culture, including literature, is in the final analysis produced by a "higher" agency who carefully hides its activities by making their outcomes appear to be erratic and fortuitous.

When it comes to discussing the historical origins of the French realist novel as developed by Balzac, it is a nearly uncontested thesis that Diderot was the most important inspiration for nineteenth-century "realism". ${ }^{446}$ By repudiating the model of classical tragedy as artificial and unconvincing, by calling for illusion instead of admiration, Diderot opened the way for a new literary paradigm whose adequate generic frame was prose fiction rather than the dramatic genre in which he himself still tried to excel. This role of precursor applies even in the case of specific devices. The technique of the tableau in particular as a means of producing illusion, which is suggested in the Entretiens sur ' $L e$ Fils naturel' (1757), ${ }^{447}$ is frequently referred to by twentieth-century scholars of the French realist novel who wish to point out the importance of Diderot.

The illusionary potential of tableaux -that is, of scenes on stage modeled after scenes of everyday life as depicted in genre paintings-has perhaps been best explained by the art historian Michael Fried, who is also a literary scholar. In his seminal book Absorption and Theatricality, ${ }^{448}$ Fried argues that a major shift in the history of (representational) painting took place in the eighteenth century: persons depicted on canvases no longer look at the beholder in a quasi-theatrical fashion, that is, as actors on stage who speak to an audience;

446 See, once again, my Ästhetik der Wirklichkeitsdarstellung (as to Diderot's concept of tableau, see specifically pp. 22-24, including the notes).

447 In: Euvres esthétiques, Paul Vernière (ed.), Paris 1965, pp. 77-175; as for the description of the device of tableau, see pp. 88-91.

448 Subtitle: Painting and Beholder in the Age of Diderot, Chicago, IL 1980. 
rather, they are modeled in such a fashion as to convey the impression of being "absorbed" in what they are doing in the depicted scene and of not caring at all about who might be observing them. In the latter case, beholders have the impression of access to what the depicted figures "really" feel and to what preoccupies them; in the former case, they are left with the sense that the figures are just performing (for them), in other words, that what they display is not authentic, but staged. It is the "absorptive" variant of graphic art which is meant when Diderot talks about tableau-like techniques of representation as adequate means of producing illusion.

The fascinating constellation, referred to above, of the production of something new and completely unintended by the originator of the pattern it employs, is described in detail by Tatiana Korneeva: she found that the device of "tableaux on stage" was not of Diderot's invention. ${ }^{449}$ He adopted (or should we say plagiarized?) it from Carlo Goldoni, who might rightly be considered the true father of the genre called drame bourgeois (a role typically ascribed to Diderot), which was later to become, transformed into narrative prose, the basis of novels like Le père Goriot (1834/1835). This fact is frequently neglected in literary history, but not totally ignored, since Diderot himself-while calling Goldoni, rather condescendingly, an "author of farces"450_admits it. The interesting connection revealed by Korneeva's study consists, however, in the fact that even Goldoni was not the first inventor of the device in question, that he was rather inspired by an obscure Neapolitan aristocrat and playwright named Domenico Luigi Barone (1685-1757). And one has to add another site of cultural activity in order to fully reveal the erratic character of literary production on display here. Barone's texts and techniques were largely inspired by the Spanish Baroque theater, which is in principle hardly astonishing; the Kingdom of Naples was in that age a colony ruled by a Spanish viceroy.

The paradox to be observed here is linked to the fact that the Spanish plays in question had little if anything in common with what was subsequently called literary realism. Without too much systematization, they may be labeled didactic dramas; they were either explicitly allegorical, or based on allegorical constellations which were superficially re-mimeticized by giving the personifications proper names. This "allegorical connection" can still be observed in Goldoni's work, for instance in plays like Il genio buono e il genio cattivo (1767), whose basic structure is more or less the same as in famous religious comedias

449 "Il pubblico teatrale nel Genio buono e il genio cattivo di Carlo Goldoni”, Italian Studies vol. 70/2015, pp. 92-116.

450 De la poésie dramatique, in : D. D., Euvres esthétiques, pp. 221-223. 
by Calderón, in this case El mágico prodigioso, for instance. In the context of the Spanish didactic plays, tableaux on stage were "real" paintings (coulisses) exhibiting allegorical scenes interpreting or reconfirming the meaning of the action of the play proper. Goldoni's idea, adopted from Barone, to mix, so to speak, the devices of mobile (regular) performance with devices inspired by static (pictorial) performance as a way of producing impressive plays thus has its roots in the allegorical Christian drama of medieval provenance, which had been renewed and updated in the Spanish Counter-Reformation. As early as in Goldoni, the device was re-functionalized from didacticism to the production of illusion. Thus reshaped, it was presented by Diderot as his own invention and used as a centerpiece of his ideas on dramatic mimeticism. But it was only when Balzac transposed these ideas from the genre of drame to the novelfrequently termed, including by the author himself, (narrativized) drame- ${ }^{451}$ that literary realism in the modern sense came into being.

The "extraction" of diverse materials and concepts from the floating processes taking place within the cultural net; the superimposition of different reshapings and re-functionalizations finally producing results which in the end have nothing in common with or are even in contradiction of the intentional dimensions of the works where one might first observe the techniques and devices in question-such processes may be paradigmatic of the productive dimensions of what I suggest calling the cultural net. Its main features are the universal availability of diverse material and the liberty of cultural producers to extract whatever they might need, to decompose it, and finally to reassemble it in a novel fashion. In some cases (Diderot), their "creations" may trigger long-lasting cultural effects; in other cases (Barone), their work may only serve subsequent cultural producers as material that calls for further dis- and re-assembly before attaining the level of general reception.

\section{“Rootedness": Johann Gottfried Herder}

0.-In terms of theoretical conceptualizing, the "antagonist" to my approachthat is, to the idea that works of art, including literature, as well as culture in general, may be conceived as products of a synthesis of items, content-related as well as formal, circulating in a universal virtual net-is, most obviously, the concept of "national literatures". Its first extensive theorization, which continues

451 For more details, see the chap. on Le colonel Chabert in my Balzac und der 'Effet de réel'. Eine Untersuchung anhand der Textstufen des Colonel Chabert und des Curé de village, Amsterdam 1986. 
to be influential up to the present, is the notion of popular culture in its acceptation as Volkskultur and Volkspoesie, developed by Johann Gottfried Herder (1744-1803). I shall link my theoretical remarks in this chapter to a specific text corpus which will allow for the assessment of the extent to which the notion of Volkskultur has a fundamentum in re, namely, popular theater culture $^{452}$ as documented in traditional, premodern Bavaria and Austria.-But before coming to the debates from the eighteenth century, I would like to formulate some remarks on how the situation might be assessed with regard to previous eras, limiting my scope to periods from which there is sufficient extant documentation to go beyond mere speculation.

1.-The Greeks of the classical period-as is the case with many or perhaps all ancient civilizations-did not concern themselves with the question of the extent to which their great texts were essentially "Greek", for the simple reason that they did not deem the literary production of other tribes or communities worth the effort of consideration. They were, to put it in current terms, communitarians. Universalism was a concept so far removed from their intellectual framework that they did not even compare their culture to that of the "others", the barbaroi. ${ }^{453}$-As a first point concerning the debate at issue, this observa-

452 For all necessary details, see Bernhart, Volksschauspiele.-There is a problem of translation involved in the topic of this chapter. Volkspoesie, Volkstheater, Volkskultur, Volksliedthese and similar terms are typically rendered in English by making use of the adjective "popular". The main difference, in my view, is that Volkskultur as well as all related terms primarily refer to the originating instances, whereas "popular" mainly refers to intended and real recipients. Pop music, for example, does not have to be created by the "common people"; the term is used to designate a genre of musical creation that appeals to everyone, in the first place to those who do not "know" anything about music (who are not able to read a score, who do not play an instrument, who are unfamiliar with musical traditions, etc.). Herder's concept of Volkskultur, by contrast, is based on the assumption that the works in question are created for, but also by the common people, in a sort of collective act that may span many generations during which an embryonic text is re-narrated again and again. The documents that have come down to us (the codices) are, according to him, not "creations", but mere recordings, that is, the result of the conversion of sound (orality) into letters (textuality).

453 Is it necessary to make explicit that this generalizing assessment is (as are all generalizing statements within the humanities) relative, that is, needs to be understood in relation to the modern Western situation? Since ancient Greeks maintained close economic relations with limitrophic tribes and empires, and also engaged in warfare with them as early as in archaic times, there was a certain knowledge of the barbarian cultures (in contrast to cases of absolute ignorance in this respect as conditioned by geological factors [communities living on islands far removed from other islands (Australia); small communities living scattered in vast territories difficult to traverse (Brazil)]). But as can be inferred from emblematic literary figuresMedea, for instance-there was nothing that could compare with the relations of exchange on an equal level and the ensuing combination of mutual esteem and agonistic competition that is characteristic of cultural relations in the West starting in the Middle Ages. 
tion may produce the insight that the emergence of a concept like "national literatures" presupposes some sort of universalism, be it an emerging one, as its background. Only when humans consider other humans as in principle equal does the question of how to define one's "own" cultural products versus those of the "others" become relevant. ${ }^{454}$-It is precisely this feature which is absent in the system of a classical school of thought that has been very influential in Western modernity and is frequently seen as a precursor of modern universalism: skepticism. The skeptics' tolerance of the "views" (manners, social codes, artworks) of any imaginable tribe is not based on the assumption of equality; it rather emanates from a less aggressive interpretation of the concept of barbarism than that found in Aristotle, who deemed it legitimate to treat barbarians in the same way as wild beasts. ${ }^{455}$ For the skeptics, the "others" and their cultures are without any importance. It is indifference that characterizes their attitude towards foreign cultures. As alien communities are committed to disinterest, there is no need to theorize what one's own culture might be in contrast to that of the "barbarians".-According to current clichés, Greek culture and self-conception underwent a radical change in the period during which the various tribes were violently unified and then bellicosely spread into regions hardly known to them before. Hellenism is a time of cultural imperialism which goes along with the partial integration of the cultural patterns of the subjugated into a "new" and more comprehensive Greek culture. Still, the processes occurring in this period did not provoke a reflection of what Greek (vs. non-Greek) culture is or was. The civilizational gap between the conquered territories and the Greek motherland was so significant that the encounter with the "others" did not irritate the pre-existing self-sufficiency of Greek reflection. Quite as was the case in later times, in the period of the Western penetration into sub-Saharan Africa for example, Greeks of Hellenistic times did not sense a need for self-reflection and self-problematization. The difference between "own"

454 The above point may also be of a certain relevance with regard to the other early high civilization, China-a community that preserved its communitarian attitude much longer than Greece (which, as part of the Roman Empire, adopted universalism in the fourth century CE), in fact up to the period when it was opened up by military intervention on the part of the Western powers. Within traditional Chinese culture, there is no relevant interest in "foreign" artworks and, consequently, no need to reflect on what the dichotomously conceived "essence" of one's own, Chinese art is.

455 See Plutarch's summary of Aristotle's advice in this respect to his pupil Alexander ( $D e$ Alexandri magni fortuna aut virtute I 6). There is much controversy regarding the authenticity of the passage, but such discussions seem somewhat superfluous. Throughout his works, Aristotle equates barbaroi and douloi (slaves, who most frequently were of "barbarian" provenance); the juridical status of the latter was that of objects, instruments, without any human dignity or any rights (see Politics 1252a 30 ff., and 1253 b 30 ff.). 
and "other" was cast as hierarchical and in addition as categorial; as long as they did not adopt Greek culture, the conquered remained barbaroi as theorized by Aristotle: intermediate beings between animals and "real" humans, meaning: Greeks.-In addition to the above-mentioned feature, tribal self-consciousness ("nationalism") seems to have a second prerequisite: the presence of various tribes of an approximately comparable civilizational level within a territory that is physically as well as conceptually manageable under a given standard of technological development.

At first sight, things appear to be different in the case of Rome; yet in essence, they seem ultimately to be the same. The Romans adopted Greek culture and literature as their own after having conquered the peninsula, partly translating or emulating the texts in Latin, partly preserving them in their original formulation. They chose the way of self-Hellenization. There was a "strong" concept of Rome as a power and regarding its mission; but there was no specific concept of an autochthonous cultural identity linked to it. ${ }^{456}$ One might speculate about the reasons for this quasi-absence of a cultural "national" identity. As occurred in Late Antiquity, when the barbaric conquerors of the Roman Empire adopted Roman culture, the distance in terms of civilizational level may have appeared so immense that the idea of casting a Roman cultural identity in contrast to Greek culture might have seemed devoid of sense; and the inverse relation in terms of physical power might have facilitated accepting the narcissistic lesion going along with the adoption of a cultural model that was not the Romans' own.-This feature of an absence of "national" cultural identity was reinforced when Rome spread its rule over the entire Mediterranean world, integrating innumerable tribes and distinct traditions into its empire; it was given another strong impulse when the educated strata of the population received Stoicism and adopted its universalizing implications; it became definitive when, in the fourth century, the empire embraced the first religion ever with a claim to universality, Christianity, thus conferring an incontestable (since divinely revealed) ideological basis upon what had first emerged contingently. ${ }^{457}$

456 The central text establishing the rising empire's self-conception with regard to its "origins", Virgil's Aeneid, does not present Rome as a product of autochthony, but rather as a product of transfer.

457 I should like to stress that the "Roman case" is apt to elucidate an implication of my above claim that universalism is a prerequisite for the emergence of the concept of different national cultural identities: it does not necessarily provoke the feature of compartmentalized cultural identity.-Given the extremely scarce extant documentation of Rome's self-reflection in the early centuries (that is, before the conquest of Greece and the adoption of Greek culture), it would be audacious to present speculations aiming at causally explaining this feature of a quasi-absence of a cultural tribal identity. With a view to further discussions regarding this 
2.-According to a widespread belief, the situation changed dramatically roughly one thousand years later, when Dante started theorizing the volgare-that is, the variant of classical Latin that had become the language of daily communication in Tuscany-as an instrument that is, at least on the level he calls vulgare illustre, no less dignified than Latin as a language for literary texts. As is well known, Dante even wrote a treatise, De vulgari eloquentia (1303/1305), concerning this postulate; but it is quite telling that he wrote it in Latin. ${ }^{458}$ Ultimately, Dante's views have little in common with what we currently understand by the term "national literature". ${ }^{459}$ The dichotomy underlying his argument is, indeed, the one of Latin vs. Italian, but not in the sense of "other" vs. "own"; what is meant is the dichotomy of grammatica vs. sermo vulgaris-that is, the standardized language of script ${ }^{460}$ vs. the language of oral communication. The grammatica is not considered to be "foreign" or "other". It was not Dante, but another

question, I would like to offer the observation that a "low-level" cultural identity-in terms of an absence of a strict dichotomizing-may be characteristic of global empires, or even a prerequisite for spreading their (military, economic) power over the entire world. The Unites States of America may be, mutatis mutandis, such a parallel case. It adopted its basic cultural features from a nation it had defeated in a war; regardless of an extremely highly developed consciousness of its "imperial" status in terms of power and influence, the USA is remarkably open to exogenous cultural material of any kind (I should stress, once again, that this book is written from the perspective of an author who has spent almost all of his life in traditional European nation-states). In both cases, it may be the point given expression to at the end of the preceding paragraph which yields an additional explanation for this fact: if there is, finally, no competitor of an approximately comparable level, there is no need for a rigid cultural dichotomizing.

458 In anticipation of my argumentation above, I should stress that the treatise is written for people writing and discussing literary texts, that is, the educated only, whereas Dante's most important text, the Commedia (1307-1321), is a didactic text, that is, a text conceived for general divulgation.

459 Regarding this point, see Dante's explicit rejection of all sorts of "nationalism" and claims to supremacy of one tribe over another, as resulting from a lack of reason and from the state of being uncultured ("Nam quicunque tam obscene rationis est ut locum sue nationis delitiosissimum credat esse sub sole, hic etiam pre cunctis proprium vulgare licetur, idest maternam locutionem, et per consequens credit ipsum fuisse illud quod fuit Ade. Nos autem, cui mundus est patria velut piscibus equor, quanquam Sarnum biberimus ante dentes et Florentia adeo diligamus ut, quia dileximus, exilium patiamur iniuste, rationi magis quam sensui spatulas nostri iudicii podiamus". // "For whoever is so misguided as to think that the place of his birth is the most delightful spot under the sun may also believe that his own language, that is, his mother tongue, is preeminent among all others; and, as a result, he may believe that his language was also Adam's. To me, however, the whole world is a homeland, like the sea to fish; though I drank from the Arno before my teeth grew, and love Florence so much that, because I loved her, I suffer exile unjustly, I will weight the balance of my judgement more with reason than with sentiment." [De vulgari eloquentia, liber primus, VI, 2-3]).

460 Etymologically, grammatica derives from the Greek gramma, "letter". Grammars or grammar books, in the modern sense of the term, are a collection of rules applicable to the written 
of the tre corone, namely Boccaccio, who made the reasons for the postulation of an equal linguistic dignity of the vernacular explicit: the knowledge of the grammatica was limited to a very restricted circle of educated people-less than $1 \%$ of the population-whereas the volgare, at least in oral form, was accessible to everyone. ${ }^{461}$ There was no ambition involved to assert a separate Italian national identity which did not exist at the time; ${ }^{462}$ the question at issue is that of an extremely limited vs. a general (potential) audience.

I am not sure that the situation changed substantively in the centuries called the Renaissance or the early modern age. The "grammaticalization" of the various vernaculars-meaning, their standardization, starting with Antonio de Nebrija's Grammar of Castilian Spanish (1492) and continued in the work done by the Académie française, established in 1635-did indeed have implications for a concept linking cultural products mediated by language to political units. Linguistic standardization was an important factor in the establishment of the modern state, that is, of political organizations governed by rules and norms universally applicable within a given territory. Yet it was not the assumption of "blood bonds" between inhabitants that formed the basis of these territories in case they emerged in this period, early modernity. As may be inferred from the history of Spain in the era of the Reyes católicos or from the history of the fragmented German principalities of the age, the logic of early modern statebuilding was that of dynastic constellations. The concept of the nation, of peo-

version of the language in question, which may be transgressed (and are, indeed, frequently transgressed) in oral communication.

461 I am referring to the proem of the Decameron, in which Boccaccio gives expression to the idea that his collection is written for a primarily female audience and, for this reason, makes use of the volgare instead of the grammatica.

462 I should like to recall that, as concerns politics, Dante was a partisan of the idea of the Holy Roman Empire and thus expected the "kaiser" to settle the situation of civil war in Italy, of which he had become a victim.-In order to avoid getting lost in details, I leave it to readers to extrapolate how I would answer to less important objections to my argument (I will indeed be addressing the more important ones). I will mention just one possible minor objection relevant to the above passage: there is, indeed, the example of Petrarch's famous canzone "Italia mia". It is not astonishing that this poem was read along Herderian lines when nineteenth-century Italians were fighting the Spanish, the French, and the Austrians in order to become a political nation, that is, as a testimony to the fact that "Italians" had been longing for national unity as early as in the Middle Ages; Dante's above-cited ideas had to be neglected, though, for this purpose. If one reads Petrarch's poem without any nationalistic emphasis, the text turns out to be a document not of "patriotism", but of nostalgia, of the longing for a period past and for the topoi where this period of the speaker's life took place. Nostalgia, however, is a universal feeling; it emanates from our incapacity to revivify the past in other ways than by remembering. Memory is always and by necessity impregnated with nostalgia, with the feeling of loss. 
ple united not only politically, that is, by constraints of power, but also by bonds of birth, by natural bonds, ${ }^{463}$ did not exist during the period in question. The link between soil, blood, and culture became a widely accepted, quasievident concept only in later times. ${ }^{464}$

3.-It might at first sight seem astonishing that the idea as such was not developed within the most extensively homogenized community of the time, that is, France. The concept of Volkskultur is rather linked to the name of Johann Gottfried Herder. Yet if one considers the hypothesis that it is not only fiction, but also the modeling of "realities" which may to a large extent obey the logic of compensation, it is not difficult to conceive of reasons why the concept of the nation as a homogeneous unitary culture-thus linking "natural" (biological, territorial) and cultural belonging-was first developed in the German-speaking territories, and particularly during the age in question. There was no political entity named "Germany" at the time, and there was no prospect of the creation of such an entity. The modern German state was not founded until 1871, roughly one century after Herder formulated the concept of Volkskultur. This concept may have been the only way to confer unity upon a fragmented territory that seemed belated in its development in comparison to other important European communities (England, France, Spain).-Herder's theorization of culture, ${ }^{465}$ and

463 The Latin noun natio, from which the modern term "nation" stems in terms of etymology, derives from the verb nasci, meaning: "to be born".

464 There is, evidently, no story without a prehistory; as to one of the cases just mentioned, one could mention in this respect the politics of limpieza de sangre (meaning: being nonJewish in terms of genealogy) implemented in Spain from the fifteenth century onward. But the decisive first element of the above-mentioned triad was missing in early modern Spain: the "right" blood bonds to be proved by anyone who wanted to avoid discrimination and, later on, persecution, were not linked, for their part, to a specific territory, but rather to the universal community of (Catholic) believers. An assimilated German or Italian whose denomination was Roman Catholic would not have had any problems being accepted as a full member of the polity in early modern Spain.

465 Specialists of Herder's work will not be satisfied by the following portrait of his positions; but, as expressed at various occasions, this is not a book written for specialists. The concession I would be ready to make is that Herder's argumentation is self-contradictory with regard to many problems, as I shall point out in the course of this chapter. But the "racial" component I will be foregrounding is undeniably a very prominent element of his entire thinking. In addition, I should stress that it is not my intention to provide an adequate and balanced précis of Herder's theorizing in its entirety or to offer speculations regarding the question of what he "really" might have thought. When it comes to the reception of Herder's ideas, that is, to their influence, the point emphasized here seems indeed to be by far the most relevant one.-At this point in the present study, readers might have realized that my approach differs from standard present-day cultural theory not least by trying to avoid any moral judgments concerning the positions discussed. As to Herder in particular, and notwithstanding the devastations some of his concepts may have triggered in twentieth-century European political history (including 
in particular of culture as language, that is, literature, formed the basis of the Romantic concept of "national culture" throughout Europe. Although such an approach to culture was relegated to the background in the age of avant-gardism, the emergence of "new" nations that went along with the collapse of colonialism revitalized it in a most remarkable way. As was the case in Europe at the beginning of the nineteenth century, the process of postcolonial nation building was accompanied by a discourse aiming at the delimitation of what is essentially one's own from that which belongs to others; or, to put it in current terminology, it was accompanied by an identity discourse.

Vernaculars indeed differ from one another; that is a fact. They are, however, hardly sufficient for substantiating the postulate of identity. The long-standing practice of vernacular multilingualism, widespread amongst the nobility and the educated parts of the middle class in Herder's day, might have resulted in the impression that language alone was an all too frail basis for postulating a cultural "identity" in a substantive fashion. The concept of Volkspoesie ${ }^{466}$ (national literature) seemed appropriate for neutralizing this lack. According to the Herderian conceptualization, popular culture and literature in particular are not the creation of individual geniuses, but rather the collective creation of the common people amongst whom they first emerged. By means of the repeated narration and re-narration of stories or "songs" over thousands of years, and before the emergence of the fixed textual products known to us, these stories or "songs" became-according to Herder-the direct expression of a Volksseele (literally: national soul, in the sense of national character), that is, of the entire set of mental parameters of the people concerned. The texts were thus conceived of as no less "rooted" than the people, that is, the common people, who may, indeed, seem to have been "rooted" quite like trees and plants in the times before the liberation of the third estate.

Nazi cultural theory), he can hardly be held responsible for the consequences some of his ideas may have produced. The issue is a different one if considered from a posterior perspective. In my view, twenty-first-century cultural theory has to take into consideration the question of why the concept of "national cultures" turned out to be as highly polemogenous as it did in twentieth-century political history; my suggestion would be to consider the hypothesis that the attempt at "proving" a conceptualization which was highly ideological (as opposed to real) might have been one of the reasons for the general radicalization of political life observable in Europe from the middle of the nineteenth through the middle of the twentieth century.

466 In eighteenth- and nineteenth-century usage, the German term "Poesie" designates not only poetry, but also narrative and drama; its equivalent in present-day standard German is "Literatur". "Poesie" as well as "Literatur" exclude all variants of low-level trivial fiction, but not valuable "popular literature" in the sense hinted at by Herder's conceptualization. 
Such a conceptualization might at first sight appear plausible due to the fact that there are certain features of human culture which are, indeed, directly contingent upon the conditions reigning in specific habitats. The architecture of houses, as well as clothing and styles of dress, nutrition, etc., are dependent upon climate and geological factors. Since literary texts are clearly different in different regions, the indicator being the difference of language, it seemed convincing to transpose this concept of the rootedness of more pragmatic cultural practices and products to literary texts, above all to popular texts, and to thus arrive at the well-known and still prevalent notion of Volkspoesie as an expression of Volksseele. ${ }^{467}$

One might add a detail regarding German cultural history which has been touched upon in passing at various occasions above: Herder's theory had an aim which is transparent on almost every page of his tracts. The culture of eighteenth-century Germany was under the sway of a strong influence from France. Noblemen as well as intellectuals mainly communicated in French. German seventeenth-century, that is, Baroque literature was considered "barbaric"-it is indeed somewhat odd, linguistically as well as conceptually-and the treasures of Middle High German literature were largely unknown at the time. Herder was one of those thinkers-they exist in all tribes and at all times, including the present-who, for whatever reason, were opposed to this early vogue of "globalization", that is, the absorption of less well-performing cultural entities by those that perform better. He was a communitarian. In order to make the claim that German culture is valuable, he could not do otherwise than to postulate that there is an "essential" difference between French civilisation on the one hand and German Kultur on the other.

467 As I shall mention in the following, the influence of Herder's ideas in the Latin world was less significant than among the Germanic and Slavic nations; but they were influential, in particular in the first half of the nineteenth century, with its cult of couleur locale. On the level of theory, Herder's ideas were an inspiration for the concepts of a theoretician as important as Hippolyte Taine, who propagated the parameters of race, milieu et moment as determinant factors of all cultural production. And even in the twentieth century, the influence of Herderian concepts may be detected in French culture. As an example, I shall quote a specifically pointed and polemical passage from Guillaume Apollinaire: "Furthermore, poets must always express a milieu, a nation; and artists, just as poets, just as philosophers, form a social estate which belongs doubtless to all humanity, but as the expression of a race, of one given environment. Art will only cease being national the day that the whole universe, living in the same climate, in houses built in the same style, speaks the same language with the same accent, that is to say never" ("The New Spirit and the Poets" [1918], in: G. A., Selected Writings, Roger Shattuck [tr.], New York, NY 1971, p. 229). 
It is striking to see the innumerable logical twists this highly learned man is obliged to make in order to invest his rather bizarre but influential conceptualization with the semblance of argumentative coherence. The most illustrative example of these logical leaps and breaches may be his portrait of English literature. ${ }^{468}$ The English tradition is presented as Germanic, and thus as the expression of a Geist that is parallel if not identical to that of the Germans residing on the continent. This assumption is "substantiated" by way of a brief recapitulation of the political history of the British Isles that gives prominence to the numerous invasions by Scandinavian tribes. There is not much room for the Celtic component of the English tradition in this narrative. Yet above all, there is no room for an event as major as the conquest of 1066. It is not mentioned at all. And yet, from that date onward, English language and culture have been a mix of Celtic, Germanic, and French elements, the latter feature linking all posterior English culture to the entirety of the Greco-Roman heritage and its Mesopotamian, Egyptian (etc.) antecedents.

Herder's blindness in this respect also informs his eulogy of Shakespeare as a Teutonic genius who supposedly gave expression to the Volksgeist of all Germanic tribes. Yet Shakespeare's use of Latin, Italian, Spanish, and Greek sources receives little, if any mention. Herder's readers are given the impression that Shakespeare's dramas mainly consist of the appearance of ghosts, witches, and other related strands appropriate for a refutation of the superficiality of rational French civilisation, represented by Racinean tragedy, in the name of a comprehensive Germanic Kultur whose attributes are linked to dimensions of a "higher" or “deeper” truth not accessible by mere reason.

4.-On a more general level, the argumentative frailty of Herder's tracts becomes apparent in a recurrent and rather amazing feature. On the one hand, the author relentlessly stresses that "authentic" culture is bound to its location and to the "tribe" (Volksstamm) inhabiting the location in question; he claims that cultures are autochthonous in the very literal sense. If that were the case, there would be "national cultures" as diverse as the planet's climate and geology (moderate climates, cold climates, hot climates; coastal, maritime spaces, plains, deserts, mountains, etc., etc.). But Herder himself again and again detects with great joy and enthusiasm that all these different cultures bear farreaching commonalities as long as one goes back in time sufficiently. The pris-

468 See the essays "Shakespear" (1773) and "Von der Ähnlichkeit der mittleren englischen und deutschen Dichtkunst" (1777); one should also read "Auszug aus einem Briefwechsel über Ossian und die Lieder alter Völker" (1773); quotes are from the standard edition (Sämmtliche Werke, Bernhard Suphan [ed.], 32 vols., Berlin 1877-1909, vol. 5, pp. 159-257 and vol. 9, pp. 522-535); translations are mine. 
tine products of the different national cultures are analogous, if not identical; in congruence with the findings of emerging evolutionary biology, Herder advocates the thesis of the species' monogenesis. ${ }^{469}$ Starting from this assumption, and in formulations to be found some decades later in myriad texts by Romantic writers, he praises the "patriarch's tent" as the first and best model of human congregation. The "values", cultural as well as societal, that developed on this "ground" are "wisdom instead of science, piety instead of knowledge, love of parents, spouses, and children instead of courteousness and debauchery. Life well-ordered, the rule by divine right of a dynasty-the model of all civil order and its institutions-, in all this mankind takes the simplest, but also the most profound delight. ${ }^{470}$ [...] The human spirit received the first forms of wisdom and virtue with a simplicity, strength, and majesty that [...] has no equal, no equal at all in our philosophical, cold, European world. And just because we are so incapable of understanding this anymore, of feeling it, let alone of taking delight in it, we mock, we deny, and we misconstrue!”471 And he ends his diatribe, directly addressing his contemporary educated readers, by devaluing "your philosophical deism, your aesthetic virtue [...] your universal love of all peoples" as symptoms of either ignorance or hypocrisy. ${ }^{472}$-Herder does not discuss explicitly what factors might have vitiated this early culture, including its literature, which was an "immediate" expression of humankind's Seele. But from the above formulations it is evident what he had in mind: it is rationality, refinement, progress, in brief, civilization that brought about the detrimental move away from literature as an expression of the Volksseele.

Herder is a (pre-)Romantic, but a naïve Romantic. He posits as "true" and "essential" what more enlightened thinkers of the age, such as Schiller, would apostrophize as a legitimate longing for a past that is past, which may be recreated by way of works of art, though under the condition that these works preserve and manifest the artificial character of the recreation. This is the essence of Schiller's concept of das Sentimentalische as opposed to das Naive; ${ }^{473}$ the latter concept designates the "authentic" vestiges of pristine human culture which exist in modernity as fragments only.-It remains an open question, however, whether such a "naïve" approach to the world ever truly existed. It may be that mediation, in other words, the introduction of language and reflection, put an

469 The following arguments are most clearly expressed in Auch eine Philosophie der Geschichte zur Bildung der Menschheit (1774), in: Sämmtliche Werke, vol. 5, pp. 475-593.

470 P. 479.

471 P. 484.

472 P. 486.

473 See On Nä̈ve and Sentimental Poetry (1795). 
end to all such "naïveté" grounded in "immediacy" (Unvermittelheit), which thus would be an attribute not of the human, but of the animal world.

5.-Before I start discussing the text corpus to which I shall link my critical remarks concerning Volkspoesie, I should like to make one additional point with regard to Herder's conceptualizations and to the innumerable theories, up to and including postcolonialism, that are more or less direct continuations of these ideas. As already mentioned in passing, it is not without reason that concepts of national culture and rootedness first arose in a German context, nor is it astonishing that they were enthusiastically received in Northern and Eastern Europe and later on in Latin America, ${ }^{474}$ in fact in the entire (former) Third World, including amongst its intellectuals. The influence of such ideas in the strongholds of occidental culture (France, Italy, Spain, England, in later times also the USA) has always been relatively limited. The explanation seems obvious: it would be devoid of sense to claim that French (or Italian, Spanish, etc.) literary culture is the expression of a Geist or Seele of tribes residing in these territories since times immemorial, for two different but intertwined reasons. It is not possible for the people living in these countries to be unaware of the fact that their ancestors have not been "rooted" in the soil for thousands and thousands of years, that they are rather the descendants of a somewhat wild mix of locals (Celts), Roman conquerors or immigrants (meaning: people from the Mediterranean in a very broad sense of the term), and Scandinavian conquerors of the Roman Empire (Goths, Vikings, Normans). Secondly, they cannot be unaware of the fact that their languages as well as their entire cultures, including their literary texts, are to a very large extent the result not of "rootedness", ${ }^{475}$ but rather of transfer, of a translatio studii accompanying the

474 It is perhaps no surprise that it was Jorge Luis Borges-amongst others, including the most famous Brazilian novelist to date, Machado de Assis-who polemicized, in his typical way impregnated with irony, against the widespread notions, arising in the age of Latin American "nation-building", of a peculiar Latin American (or even Argentine, Mexican, or Brazilian) literature: "The idea that Argentine literature must abound in differential traits and in Argentine color seems to me to be a mistake. [...] Furthermore, I don't know if it needs to be said that the idea that a literature must define itself by the differential traits of the country that produces it is a relatively new one, and the idea that writers must seek out subjects local to their country is also new and arbitrary. [...] The Argentine cult of local color is a recent European cult that nationalists should reject as a foreign import." "“The Argentine Writer and Tradition”, in: J. L. B., Selected Non-Fictions, Eliot Weinberger [ed.], Esther Allen [tr.], New York, NY 1999, pp. 421-427).

475 Let me say in passing that the most important French precursor of Romanticism, Rousseau, bases his description of the early sedentary communities, no less tainted by nostalgia than Herder's, not on the assumption of family ("blood") bonds between members, but on the concept of contract (contrat social). This said, one may detect-as I shall briefly explain in the followinga strong influence of Herder's ideas in the two or three decades of "acute" Romanticism in 
translatio imperii. In the Latin parts of Europe, including England, culture evidently emanates from network-like structures and their constant and finally uncontrollable ramifications. ${ }^{476}$

France, namely in authors like Chateaubriand and Lamartine (see my "Sentimental Revivals: Gérard de Nerval's Voyage en Orient”, in: Stephen G. Nichols, Joachim Küpper, and Andreas Kablitz [eds.], Spectral Sea: Mediterranean Palimpsests in European Culture, New York, NY and Bern 2017, pp. 157-202; Nerval's text contains massive ironizations of the basic concepts of Romanticism as displayed in his predecessors' "oriental" travelogues; it was published in 1851, that is before Flaubert's Madame Bovary and Baudelaire's Fleurs du mal, which both appeared in 1857).

476 The history of literary studies is an example of the paradoxical impact generated by Herder's ideas all over Europe. Vernacular literary studies as a discipline taught in universities is, all over Europe, an "invention" of the early nineteenth century. It did not exist previously; traditional humanistic literary studies treated the classical texts (Greek and Latin) only. The following fact might be hard to believe: French literary studies were first established in Germany, in the newly founded, Humboldtian University of Bonn, by Friedrich Diez, the first professor ever appointed to the study of Romance languages and literatures (1830). It is not very difficult to imagine that literary studies at early nineteenth-century German universities were practiced along Herderian lines. And there is, indeed, one segment of postclassical European literature (texts to which I shall come back later) that ideally fits the Herderian parameters, namely, medieval texts. Consequently, modern (nineteenth-century) literary studies were originally almost exclusively medievalist. As Middle High German texts are to a large extent based on French models, the first modern literary scholars in Germany had to study not only their "own", but the medieval French texts as well-which were largely unknown in their country of origin at that time, with the exception of the lyrics of the troubadours. This latter portion of the French literary patrimony had been rediscovered already by François-Juste-Marie Raynouard (Choix de poésies originales des troubadours [1816-1821]), who was deeply influenced by Herderian concepts; his endeavors were carried on by Claude Fauriel, the first-ever professor at the Sorbonne to hold a chair for "littératures étrangères" (1830). Fauriel had absorbed the basic concepts of German Romanticism as a close acquaintance of Mme de Staël, author of the famous book titled De l'Allemagne (1810), which is generally regarded as the first manifestation of Romantic ideas in the French language. Scholars like Gaston Paris, who had studied with Diez, began to systematically establish French literary studies, emulating the "German" style, that is, the emphasis on medievalism. In 1835, Francisque Michel, a young scholar inspired by these new ideas, traveled to England. In the Bodleian Library, he found the manuscript of the Song of Roland and thus "created" what has since been regarded as the French national epic. Paris and his followers adopted the Herderian notions of "rootedness", although, as I express above, these do not make much sense in a French cultural context (this is, by the way, the reason why the very first "Herderian" medievalist in France, Jean-Charles-Léonard Simonde de Sismondi-an amateur scholar, much better known as an economist-had excluded French literature from his De la littérature du midi de l'Europe [1813]: it is all too obviously influenced by classical [Latin] models and thus does not fit the Herderian parameters). It constituted another decisive step, leading directly to what literary studies has been in French universities up to the present, when pupils of these medievalists transposed the concept of "national literature" to more recent periods. Herderian concepts thus became highly influential into the twen- 
The difference, I would argue, between the case of these parts of Europe and that of regions such as the Germanic lands, Eastern Europe, and those parts of the former Third World which were not totally absorbed into Western culture during the process of colonization ${ }^{477}$ does not even consist in a fundamental dissimilarity between their respective situations; it is the consciousness of the situation that differs. The fact that "tribes" as well as "tribal cultures" are nothing stable and "rooted", but rather the result of constant processes of exchange of genes and memes, cannot remain hidden in ages when the documentation of the past has become a routine practice. The French (and the Italians, Spanish, etc.) know from written evidence what their history has been from roughly the first centuries before the Common Era onward; and they are not able to deny what they and everyone else knows, however strong their longing for "rootedness" may be. In these countries, Romanticism-with the exception of brief periods-has always remained a mindset of the uncultured, the peripheral and nonintellectual parts of the population. In the Germanic territories, the past is known only from the age of Charlemagne onward; as to Eastern Europe, the threshold of documentation is situated even later in time. Since substantial written records are lacking, Central and Eastern European nations have a tendency to construct a past, building their construals on the basis of their longing for certainty and stability in a world where these do not exist, where "substance" is nothing but a phantasm. The political and ideological instability of many of the Central and Eastern European nations (as well as nations of the Third World ${ }^{478}$ )

tieth century, and they continue to be so in present-day literary studies not only in France and Germany, but all over Europe (for details, see Hans Ulrich Gumbrecht, "Un souffle d'Allemagne ayant passé: Friedrich Diez, Gaston Paris, and the Genesis of National Philologies”, Romance Philology vol. 40 / 1986/87, pp. 1-37).

477 As for Latin America, where this total absorption did occur, the enthusiastic reception of Herderian ideas is linked to a massive re-valorization of the pre-Columbian heritage. Similar to what happened in eighteenth-century Germany, but on a frailer basis (since there is not much left from pre-Columbian times), the rediscovery of the "autochthonous" tradition is part of the attempt at emancipating the Latin-American nations from the culture of the colonial "oppressors".

478 The great nation and culture of India first became westernized by physical force, but later on adopted Western ideals (equality, democracy) on its own volition; with certain qualifications ("people's democracy" instead of Westminster-style democracy), this description also applies to another of the great nations and cultures of global history, China. When presentday Chinese party officials make it their task to reassert a "Chinese identity" by fending off detrimental "western influences", they are not aware of the extent to which they are unconsciously reproducing and thus falling prey to a basic concept of western Romanticism. One can only pray to the gods that Chinese leaders will become conscious of this constellation before they give in to the temptation of instigating nineteenth-century-European-style tribal wars.-Why does India seem to perform better on the stage of global politics? In contrast to China, India never knew the situation of the numerical predominance of one ethnic community 
is, at least in part, closely linked to the fact that their historical belatedness favors attitudes of self-reflection that come close to a loss of touch with reality.

6.-In order to demonstrate in concreto the extent to which current clichés about "authentic" popular culture are biased by a combination of wishful thinking and ignorance, I shall address a text corpus which seems particularly well suited to a further scrutiny of the Herderian conceptions.

Popular theatrical culture flourished in the southern regions of the Germanspeaking territories in the period in question. In the northern Germanic world, even in territories with a population mixed in terms of religious denomination, the culture of popular performance never recovered from the blows inflicted upon all performances apt to stimulate the passions by the Protestant Reformation, which followed Augustine's and Plato's denunciation of spectacula. In southern Germany and in Austria, by contrast, there was an early modern theatrical culture which at first sight seems to be a quasi-ideal realization of Herder's concept of Volkskultur: the performances were arranged without professional organization (such as that of theater companies or wandering troupes), being orchestrated instead by amateurs, that is, the common people. They took place all over the region, even in villages of no more than 100 or 200 inhabitants. The seasonal period of the performances comprised the weeks following the harvest (the second half of August, the first half of September), when the village population was temporarily free from otherwise permanent agricultural labors and the meteorological conditions were still clement-which was a necessity, since the performances were held out of doors. The initiative to organize and stage the pieces lay in the hands of groups organized according to the "democratic" principles of brotherhoods. ${ }^{479}$

All of these factors, as well as others that could be listed, would at first sight seem to yield a perfect basis for producing plays that might teach us, two hundred years later, interesting facts about the nature of the Volksseele of the Germanic population of the Alpine valleys. But when one goes to the archives and studies the historical records-as yet unprinted manuscripts of the performances which were most probably written down by village priests or administrative

(in China: the Han); religiously, linguistically, and in terms of mores, India is a culture of myriad facets. To claim an Indian or Indic identity in terms of dichotomies ("us" vs. "the others") is much less favored by the realities than in other parts of the world, including the European nation states.

479 For details, see Bernhart, Volksschauspiele; see also Toni Bernhart, "Imagining the Audience in Eighteenth-Century Folk Theatre in Tyrol”, in: Gvozdeva et al. (eds.), Dramatic Experience, pp. 269-288. 
officials-one discovers a very different picture than that suggested by "Herderian" conceptions. The plots of these plays, which were "popular" not only in terms of the spectators, but also in terms of the performers-who, in turn, were the initiators and organizers (the "creators") of the performances-were in most cases drawn from biblical history or from the classical mythological tradition; for example, a figure as "exotic" as Phaethon is frequently included in these works. ${ }^{480}$ Well-known vernacular texts which had attained a Europewide standing, such as the story of Griselda, were often made use of. There were also historical plots, dramas dealing with the Scottish Queen Mary Stuart presented as a martyr, or with Martin Luther exposed as an incarnation of the Devil. Finally, the entire hagiographical tradition is made use of in order to produce attractive plots. As a comic figure, the Hanswurst (created in Vienna) almost always appears. The texts as such are composed of spoken as well as sung passages; the latter follow the alternation of arias and recitatives as known from the elite genre of opera. In cases where the scores are still extant, it is obvious that they were modeled on the works of the famous metropolitan composers of the age, Bach, Händel, Mozart. ${ }^{481}$ The only local feature to be detected in the manuscripts is, indeed, language. The texts are not written in standard German, but in the various dialects in use at that time in the respective locations of the performances.

To put it succinctly: there is close to nothing in these instances of "authentic" popular or folk culture ${ }^{482}$ that is "chthonic", rooted, in the literal sense. ${ }^{483}$

480 The reasons for this latter predilection seem evident: the story of Phaethon perfectly fits the didactic needs of patriarchy. I leave it to readers to add the corresponding speculations with regard to the other privileged plots mentioned above.

481 Regarding this point, see Franz Gratl, "The Role of Music in Folk Drama: An Investigation based on Tyrolean Sources”, in: Bernhart et al. (eds.), Poetics and Politics.

482 That is, in contrast to the centers and their "sentimentalizing" appropriations of the strands of popular culture that may appeal to evasive desires.

483 There is a plethora of similar phenomena one could adduce in order to further substantiate my point. The best-known may be the Ossian scandal: the "translation" produced by James Macpherson, allegedly based on authentic Gaelic oral material, turned out to be a fabrication. Another example of a quite different order might be the folk dress (the German word is Tracht) allegedly worn in the Alpine parts of Bavaria since times immemorial; as Oktoberfest has become a popular item of global event culture over the last decades, this garb, supposedly "authentic" and "ethnic", has become familiar worldwide. It is not even necessary to refer to learned books produced by historians specializing in Bavarian history in order to grasp the constructed character of the supposed authenticity and rootedness of this garb. The economic basis of the Alpine regions was agricultural up to the age of industrial production and mass tourism. As in all mountainous regions, the productivity of the soil was low, meaning people were very poor. Before the introduction of industrial textile production, fabric, and all the more multicolored fabric, 
Excluding language, there are no such autochthonous elements. Consequently, the idea of a specific "identity" of the people in question that is given expression by way of these folk plays is somewhat problematic. Every item in the plays is the result of acts of extracting material floating in the cultural net and of reconfiguring it according to local demand. And there is not much speculation required when it comes to discussing the question of the material process of transmission. The infrastructure of this part of the net, spreading out to valleys which are in some cases difficult to reach even in our times, was constituted by traveling humans, mainly priests, but also state officials who carried all the items mentioned above in their mental baggage, as it were, without being conscious of this fact.

What is known about cultural life in medieval Europe in general allows for the postulate that performance practices existed in these remote regions from the earliest times, if only at an elementary level-as in the case of other cultures analyzed here which did not develop an elaborate theatrical tradition of their own. Does it make sense, then, to maintain-in accordance with classical Marxism-that the "authentic" local culture of the Middle Ages was later suppressed by the itinerant officials of the ruling class and replaced with the plots and stories mentioned? In the age we are dealing with, the places concerned presented no danger of a regionalist revolt that could have put the central power in Vienna at risk; it thus would have been highly probable that the government or ecclesiastical agents under whose patronage the performances took place would have integrated local plays or at least local features into the repertoire, had there been any. But it seems that for various reasons discussed in other parts of this book, the imported stories mentioned above were attractive from the perspective of the "creators" as well as the target audiences; they may have appealed to the needs recipients try to satisfy by attending performances. And, considered from a Lévi-Straussian or Maussian perspective, these stories and plots taken from "higher" strands of culture were, perhaps, nothing but particularly well-wrought variants of universal narratives which, as such, might have existed in the minds and practices of those inhabitants of remote alpine villages before they became connected systematically to the cultural net, in a first step by the process of Christianization, and in a second step by the introduction of the modern, absolutist State.

was a luxury good which only the wealthy parts of the European population could afford. In short: this garb is not at all based on a long-standing ("identitarian") cultural tradition; it was literally invented in the age of Romanticism, mainly by elementary school teachers, that is, people who had acquired a certain level of education and had absorbed primitivized variants of Herderian-Romantic thinking during the period of their studies in Munich. 
The text corpus to which I have linked my critique of Herder's concept dates from the eighteenth century; ${ }^{484}$ going further back in time, I should first like to refer to my above remarks on Herder's somewhat striking portrait of Shakespearean drama. But it has to be mentioned that there is, of course, strong evidence for a conceptualization along Herderian lines if one considers periods predating humanism, namely with regard to classical as well as medieval epic literature. ${ }^{485}$ It is quite plausible to assume that, after Charlemagne's military campaign in northern Spain, there emerged idealizing oral narratives created by those who were part of the enterprise. It may well be that these elementary stories were re-narrated again and again, including by illiterate people, that they became subsequently enriched with more "learned" material, that their idealizing tendencies became stronger and stronger-until one day a scribe sat down in his study and fixed on parchment what is nowadays known as the "Oxford Roland".

So, in the final analysis, the issue is not whether or not there are collective (popular, or rather folk-based) processes of cultural creation. The critical point is quite another one, namely, whether, when we are dealing with "pristine" collective textual products, different tribes (Völker) indeed produce works of art that are so different as to warrant ascribing to them a specific Geist expressing the mentality of the specific tribe in question and no other. Finally, the controversy is about whether there are indeed tribal mentalities that diverge to such an extent as to make dichotomous claims appear sensible (a German Volksgeist that is basically different from, or even opposed to, a French esprit; an "Aryan" Geist that drastically differs from a "Semitic" mentality, etc.). Is there a substantive difference between the radical deconstruction of a concept as widespread and as cherished by all humans-for evident reasons-as "blood bonds" or "family bonds" to be found in classical Greek mythology on the one hand and Teutonic mythology (the Nibelungenlied) on the other? And what differentiates, in the final analysis, the one-dimensional heroism of Roland from the attitude of those valiant warriors in the Iliad who finally fall prey to their heroism? Finally, are the differences between a Greek fighter tried by fortune and fate who is in the end restored to his riches and his loved ones (Odys-

484 I would like to highlight that the stress is on "texts"; it is highly probable that there were earlier written outlines of the plots or even rudimentary manuscripts going back to the seventeenth or sixteenth centuries which were not preserved.

485 As to classical epic literature, the explanation offered above with regard to the Song of Roland might apply as well. Before it was written down by a man called Homer, the story contained in the Iliad might well have circulated as an oral material based on "authentic" reports of the events delivered by the warriors involved in the fights. 
seus) and a Spanish warrior (the Cid) who has to suffer a similar period in his life significant enough to substantiate the postulate of diverse "national" spirits? I could go on by referring to non-"Western" narratives and their basic features, to the Epic of Gilgamesh as well as to the already mentioned mythical narratives of the ancient Mayas. There are many more factors in cultural and literary history which point to basic commonalities between cultural traditions of all kindsbe they grounded in anthropological constants or in permanent processes of exchange-than there are factors that evidence essential differences.

\section{“National Literatures": Topoi and Languages}

0.-There may be objections to the conceptualization of literary traditions developed in this study which take as their starting point a text corpus that is beyond its temporal frame, but of particular importance for all (Western) literature of the more recent past, namely the nineteenth-century European novel, especially those texts commonly subsumed under the heading of realism, that is, texts by Dickens, Balzac, Flaubert, Tolstoy, and Fontane, to mention just a few well-known authors. Perusing these novels and studying them ${ }^{486}$ may, indeed, give readers the impression of experiencing the essence of "Frenchness" or of "Prussianness", that is, of the specificity of life in Paris or in the remote province at the time of Charles X or of Louis Philippe, or in Prussia during the era of Bismarck. Taking this mighty strand of literary realism into consideration-a tradition which has been declared obsolete many times, yet continues to flourish, in particular in North America, but also in Europe, where it experiences most impressive renaissances or even "resurrections" again and again, usually right after having been declared definitively "dead" a couple of years before-is it sensible to hold that a category like "national literatures" is misconceived right from the start?

486 Starting with my doctoral dissertation, I have published a good deal (and continuously) on the nineteenth-century European novel and on the theoretical issues involved in the notion of realism (Balzac und der 'Effet de réel'; Ästhetik der Wirklichkeitsdarstellung; Zum italienischen Roman des 19. Jahrhunderts. Foscolo, Manzoni, Verga, D’Annunzio, Stuttgart 2002; “Das Ende von Emma Bovary”, in: Hans Otto Dill [ed.], Geschichte und Text in der Literatur Frankreichs, der Romania und der Literaturwissenschaft. Festschrift Rita Schober zum 80. Geburtstag, Berlin 2000, pp. 71-93; "Mimesis und Botschaft bei Flaubert”, Romanistisches Jahrbuch vol. 54 / 2003, pp. 180-212; “Considérations sur Salammbô”, MLN vol. 125 / 2010, pp. 731-782; "Fiacre et grenier. Quelques remarques sur Madame Bovary et Effi Briest”, in: Christoph König and Heinz Wismann [eds.], La lecture insistante: autour de Jean Bollack, Paris 2011, pp. 255284). 
1.-The question is evidently linked to the device of description, especially the description of places, that is, to literary topography. Balzac's famous portrayal of the quartier latin, which culminates in a description of the pension Vauquer, where the young Rastignac will spend his first two years in the capital, and where he will decide to do everything he can in order to leave such pettybourgeois misery behind for the rest of his life; Flaubert's description of the city of Rouen when Emma Bovary first sees it and is fascinated by this modern "Babylon", hence ready to behave as people in such cities do; ${ }^{487}$ or Fontane's description of the winter landscape on the shores of the Baltic Sea, which, by conveying an atmosphere of oppressive provinciality and the sense that "nothing will ever happen here", makes it all the more plausible that Effi Briest succumbs to the sophisticated seduction techniques of Crampas ${ }^{488}$-all these, and a number of other famous sequences from famous novels, seem to be inextricably linked to specific places which we are used to taking as emblematic, that is, as places in which the "essence" of specific national cultures of specific periods is concentrated.

First of all, I should like to make the trivial point that there are no such descriptions in dramas (or in poetry). In the case of drama, recipients are typically given some information concerning time and place, but these indications almost always remain on a very elementary level. At the beginning of Hamlet, we are told that the castle where the action takes place is located in Denmark, but there is nothing particularly Danish about the place or the people living there. ${ }^{489}$ The same holds true in the case of the Polish setting of Calderón's La vida es sueño or the Spanish setting of Corneille's Cid, and even more of the “Trézène” or the "Athènes” of Racine's Phèdre (1677). And even if the action is set in the same broader period as the composition of the play and in a region where the language of the play is the official vernacular, as is the case with Shakespeare's histories and, in a later period, the dramas of Ibsen and Strind-

487 “Cela se fait à Paris” is Léon's argument convincing Emma to get in the coach in which their first sexual encounter takes place (quotes are from the first chapter of the third part of the novel).

488 The first adulterous encounter takes place inside a sleigh, when the Briest couple and a number of other people are riding home after a most boring New Year's reception in a nearby village (see chap. 19).

489 It is well known that the drama does discuss (albeit not very frequently) the question of what it means to be Danish. The most detailed answer provided in Shakespeare's text is that Danes are heavy drinkers (1. 4. 16-18); given the present-day statistics on alcohol consumption in European countries in general, which seem to describe deeply rooted habits, one is inclined to say that if national character is based on nothing else, there is no such national character, at least not in Shakespeare's play. 
berg, one does not tend to see these plays as instances of a specific Britishness or a specific Scandinavianness. ${ }^{490}$-The only relevant difference between such plays and narrative texts written in the same languages consists in the fact that in the one case there is topographical description whereas in the other there is none or close to none. From a theoretical perspective, this might at first sight lead to the assumption that there are "national literatures" on the one hand comprising the genre of the novel, particularly the realist novel, and more or less transnational or non-national genres on the other (drama, poetry). Put in a nutshell in this manner, the extent to which such a view is misconceived becomes apparent. Yet it must be said that what I have just formulated is, by implication, the tacit basis of current studies in the field of literary history. The propagation of Herder's concepts was fueled by the "rise of the novel" to the status of dominant genre, a process which began at the start of the nineteenth century.

It seems that the concept of "national literature" is generated by the non-problematized (over-)interpretation of the bonds literary texts of any kind necessarily maintain with the extra-literary reality from which they originate. The most important of these bonds is language, which is a given for any literary text. Leaving aside such experiments as Ludwig Lejzer Zamenhof's strictly non-national language, Esperanto, there is no denial that every literary text is written in a specific language that originates from a specific community, a point I shall discuss separately below. The second feature which links fictional texts to factual realities, nurturing the illusion described above, is indeed topography. Since places (cities, mountains, lakes ${ }^{491}$ ) and landscapes are "realities", a literary text which marks its fictional topography by giving it the name of an existing place is more or less inevitably conceived of by recipients as "organically"

490 Regarding this point, see once again the aforementioned polemics of Machado de Assis and Borges against the Herderian, Romantic conception of literature: "I shall [...] ask if Hamlet, Othello, Julius Caesar, and Romeo and Juliet have anything to do with the history of England or the British territory, and if, nevertheless, Shakespeare is not, as well as a universal genius, an essentially English poet" (Notícia da atual literatura brasileira. Instinto de nacionalidade" [1873], in: Joaquim Maria Machado de Assis, Obra completa, Rio de Janeiro 1962, vol. 3, pp. 801-809; my translation); "I think that Racine would not have begun to understand anyone who would deny him his right to the title of French poet for having sought out Greek and Latin subjects. I think Shakespeare would have been astonished if anyone had tried to limit him to English subjects, and if anyone had told him that, as an Englishman, he had no right to write Hamlet, with its Scandinavian subject matter, or Macbeth, on a Scottish theme" ("The Argentine Writer and Tradition”, p. 423).

491 One might think of the wonderful description of Lake Como at the beginning of Manzoni's I promessi sposi (1827/1840-42). 
linked to this specific place. The more detailed the descriptions are and the more "real" items they contain (famous churches, well-known streets, topographical characteristics of any kind in the case of landscape), the more recipients are inclined to see the entire story as linked to this specific place and thus as emblematic of its specificity, that is, as substantially different from stories that could have happened in other places during the same time.

I would like to come back to two famous novels mentioned above: what is, in essence, the difference between Madame Bovary and Effi Briest? There is indeed a huge difference; Fontane's most famous novel is not a simple rewriting of Flaubert's text. One might formulate the primary difference as one of atmosphere (Stimmung). The somewhat "overheated" and hyperactive temperament of Flaubert's heroine, culminating in her dramatically staged suicide, is countered by the reserved and subdued mode of talking and acting of Fontane's most prominent female figure. Even so, the plot line-a young and naïve woman lured into a marriage of convenience to an older man she hardly knows; the incongruence of the couple's characters, needs, and desires; the relative stupidity of the (benevolent) husband, who does not realize that his wife is unhappy; the frustrated wife's falling prey to an experienced seducer; the gloomy ending with the heroine's premature death; the lasting incomprehension of the entire constellation on the part of the mourning widower-all this is basically parallel. Differences in detail are mainly linked to the difference in social class of the central characters. But the classes as such-the petty bourgeoisie on the one hand, the nobility serving as high-ranking state officials on the other-are not at all specific to the "national cultures" in question. It would be possible to identify all those features of Fontane's text, including the psychic profile of the heroine, for which there is no direct equivalent in Flaubert's text, in other realist novels from the French tradition which are set in a social sphere comparable to that of Effi Briest; in particular, one might think of Balzac's Le Lys dans la vallée (1836).

With respect to topography-where there is, indeed, a substantial differenceI would argue that the integration of "real" extra-textual material into a literary text gives recipients the illusion that the link between the story and the "real world" to which it refers is not unidirectional, but rather operates in both directions. Since the action of Madame Bovary is set in nineteenth-century Norman$\mathrm{dy}$, recipients tend to believe that this action is typical of the provincial France of that age. Logically seen, the operation just described reverses the proposition. In the narrative sequence mentioned above, it is not the city of Rouen as such that is of any importance; it is Rouen as a paradigm of the "big city" that is made use of to render Emma's actions plausible, which are not at all specifi- 
cally French; unhappy marriages seem to be a rather universal phenomenon. Mutatis mutandis, the same holds true with respect to Fontane's description of the desolate Pomeranian coast. And in Balzac's Père Goriot, the portraits of miserable Paris on the one hand and splendid Paris on the other have the function of motivating what the entire text is about: ambition ("parvenir! Parvenir à tout prix" ${ }^{492}$-an impulse that is, at least according to the Hebrew Bible, the most fundamental and universal characteristic of human beings.

2.-Still, doesn't the argument here expounded reduce literary texts to a collection of motifs? Or to a collection of pre-existing elements, including motifs, formal structures, profiles of personages, and pragmatic (non-literary) discourses of many kinds? The main difference between my approach and existing framings of the nature of literary texts and cultural products in general consists in my rejection of the view that there are substantive intermediate levels between what I call the material circulating in the net and actual, individual works. The individual work is specific; otherwise it is nothing but an instance of trivial literature whose mark is pervasive standardization. As mentioned above, Fontane's text is indeed different from Flaubert's. What is questioned by me is the assumption that this difference consists in the one novel being a typically "French" version of the story of a woman in an unhappy marriage and in the other being a typically "German" or "Prussian" version. The fundamental difference is rather one of individual ingenuity. The differences regarding "real" extra-textual material (the reference to Catholic cultic practices and officials in Flaubert, to Protestant ones in Fontane; the reference to sous-préfets in Flaubert, to Landräte in Fontane; the reference to endlessly stretching meadows in Flaubert, to the endless sea in Fontane, etc.) are necessary components of texts of this genre from the century in question; the specificity of these components is irrelevant to the problem of what makes the texts in question great works of art, even if we reject, for the time being, an orthodox "Kantian" reading of them. This irrelevance is underpinned by the fact that readers totally unfamiliar with the "real material" integrated into the respective texts-people who have never traveled to Normandy or who have never had the occasion to experience the Prussian territories known as ostelbisch ${ }^{493}$-read them with

492 I quote from the edition of the text to be found in vol. 2 of the Comédie humaine, Marcel Bouteron (ed.), Paris 1963 (Bibliothèque de la Pléiade), pp. 847-1085, quote: p. 935.

493 Do I have to stress that for a West German of my generation (I was born in 1952), this latter constellation did indeed apply to all of my readings of Fontane's novels which occurred before the reunification of Germany (1990)? Although I never experienced the regions "described" in these texts before the age of maturity, my impression as a young person (a very naïve view, as I would now say) was that the rendering of the landscape in Fontane was in perfect accordance with "reality", and that the personages and their interactions were "typically” Bismarckian-Prussian. 
great delight, indeed with no less delight, it seems, than people from the "national cultures" from which the texts respectively originate.

3.-The intricate questions discussed in this chapter have not only a production-oriented, but also a reception-oriented dimension-which, for reasons of the homogeneity of the theoretical approach, has for the most part been passed over in my overall argument so far. Yet this dimension cannot be entirely discarded, as it is, indeed, essential for a comprehensive theory of literary textswhich, however, is not the ambition of this book. I shall thus offer no more than some remarks in this respect. ${ }^{494}$

In the ninth chapter of the Poetics, ${ }^{495}$ Aristotle situates the literary text, drama and narrative, by relating it to both historical and philosophical texts, coming to the conclusion that it shares certain features with these pragmatic textual categories. History, according to Aristotle, deals with "particulars" ("a 'particular' means, say, what Alcibiades did or experienced"); ${ }^{496}$ as such, it is relevant only to readers who take an interest in the specific events recounted. Philosophical texts, by contrast, convey messages that are non-specific and abstract, that is, "general" or "universal" (katholou). Literary texts-fictional ones, but also those with an authentic substratum-are conceptually a sort of hybrid; they present "particulars", while they are "more philosophical" (philosophoteron) than historical texts. They narrate "events", that is, items clearly situated in space and time and related to individual people. Yet their message, Aristotle argues, is located on the level of the katholou: they convey something more general.

In the course of the rather succinct presentation governing this chapter of the tract, ${ }^{497}$ there is no specification of this postulate. ${ }^{498}$ But my goal is not to

494 Readers might wish to consult my essay "Das Denken, das Unterscheiden und die Literatur”, where the following argument is developed in detail.

495 Poetics 1451b.

496 Astonishingly, if considered from a modern perspective and thus from the perspective of the way in which history is written in modern times, Aristotle seems to consider historiography to be bound to do exactly that, and nothing more-which would mean that at least in this passage (perhaps for the sake of argumentative coherence), it is chronicle-style texts which he is referring to, rather than, say, Thucydides' works.

497 The Poetics belongs to the so-called esoteric part of the Aristotelian corpus, meaning, to the texts written for the internal purposes of the academy where Aristotle taught, and not for a broader public. This context explains the at times rather uneven course of the argumentation. There are numerous passages indulging in details of minor importance and others where exoteric, specifically modern readers might wish to receive additional information in order to fully grasp the argument.

498 One may infer from other passages of the tract that the "more general" concepts which, according to Aristotle, need to be contained in literary texts are meant to refer to the causal chain linking the events recounted; literary texts are to be more consistent in terms of logic 
produce a "correct" exegesis of the Poetics. Rather, I shall take the liberty to consider Aristotle's brief remarks as the first theoretical articulation of the way recipients consider literary texts in contrast to documentary texts. And I should like to add just one thought to this argument, which might even be my own contribution to the debate: ${ }^{499}$ In the case of many literary texts, this "general" or "universal" level is not just "there"; it is not something made explicit by the author. Rather, it is a dimension whose existence is assumed by the readers. For what, after all, should the meaning of an invented story about people who never actually existed be, if not the allegorical encoding of something more abstract, which becomes evident when one takes these fictional lives into consideration? Such narratives may be disregarded as meaningless or as idiotic in the etymological sense, as having a meaning only to the author who produced them. If, however, we agree to consider them as meaningful, this dimension cannot be found on the level of the specific action narrated, since we know it to be fictional; it can only be extrapolated by assuming that the individual events are instances of a "more general", a more abstract, a conceptual level of meaning.

It was the twentieth-century semiotician Yuri M. Lotman who continued the discussion regarding the "ontological" status of literary texts initiated by Aristotle, while going beyond the somewhat restricted or vague understanding of the katholou as it can be derived from the Poetics. Taking a famous novel by Tolstoy as an example, he arrives at the following conclusion, which deserves to be quoted in its entirety; thanks to its rigorous argumentation, it does not require commentary:

Thus the plot of Anna Karenina reflects, on the one hand, a certain narrow object-the life of the heroine, which we are fully capable of comparing with the lives of individuals who surround us in everyday life. This object, which has a proper name and all the other trappings of individuality, constitutes only a part of the universe reflected in art. [...] [T]his same subject [plot] [...] is a reflection of another object which tends to expand without limit. We can regard the life of the heroine as a reflection of the life of any woman belonging to a certain epoch and a certain social milieu, [or as a reflection of the life of] any woman, [or of] any person [of any human being]. Otherwise the tragic vicissitudes of her life would only be of historical interest, and would simply be boring for a reader far removed from the special task of studying the life and manners of past epochs. ${ }^{500}$

than enumerations of random events. There is an interminable discussion amongst specialists on the question of whether the causality Aristotle has in mind is restricted to the relation of a given character to her or his concrete actions or whether what is at stake are the more general rules governing the human or rather the social world.

499 Or perhaps I read it somewhere and forgot that the idea is not my own.

500 The Structure of the Artistic Text, p. 211. Additions in brackets are mine. 
To this quote-which is of capital importance for the semiotics of fiction-I should like to add one further remark concerning writers such as Kafka and Borges: The particulars some of their texts deal with are obviously not "real"; even the option of tentatively casting them as possibly real is excluded; they are fantastical, that is, they are evidently inventions of an ingenious mind. In such cases, readers proceed immediately to an allegorical level in order to confer sense upon what cannot be taken to be in any respect documentary. It may be that the absence of a literal level assignable to "real" places and "real" periods is, to a significant extent, at the basis of the continued global popularity and enthusiastic reception of the above-mentioned texts. They clearly transcend cultural boundaries of all kinds.

4.-Still, there might be some reluctance to accept the above reasoning with regard to an important subgenre of the realist novel, namely, the historical novel as first created by Walter Scott and continued in famous texts by Stendhal, Balzac, Tolstoy, Flaubert, as well as by a host of writers of the twentieth century, one of the most recent masterpieces being Gabriel García Márquez's novel on Simón Bolivar, El general en su laberinto (1989). ${ }^{501}$ These texts link the narrated plot not only to specific places, but also to specific periods, particularly to periods that are highly individualized-that is, to events we consider turning points of history, or rather of the specific history of a specific community, a feature that would make such novels, at least at first sight, rather uninteresting for readers whose "belonging" ties them to spatiotemporal parameters far removed from those thematized in the respective texts.

The most lucid writer and theoretician of the genre, Alessandro Manzoni, reflected on its conceptual basis again and again, finally coming to the conclusion that the historical novel is indeed a "componimento [...] intrinsecamente contradittorio"502_by which he refers to the fact that historical events are always and by necessity particular, whereas fictional events and plots only make sense when readers are willing to attribute to them a "more general", that is, an abstract meaning in the sense already theorized by Aristotle. In logical terms, the argument is hardly refutable.

501 See my “Re-Historisierung, De-Historisierung. García Márquez’ Bolívar-Roman als Musealisierung eines geschichtsphilosophischen Mythos (El general en su laberinto)", in: Ulrich Schulz-Buschhaus and Karlheinz Stierle (eds.), Projekte des Romans nach der Moderne, München 1997, pp. 195-236.

502 For a detailed analysis of I promessi sposi, as well as of the tract Del romanzo storico, see my "Ironisierung der Fiktion und De-Auratisierung der Historie. Manzonis Antwort auf den historischen Roman (I Promessi Sposi)”, in: J. K., Zum italienischen Roman des 19. Jahrhunderts, pp. 52-84; quote: Del romanzo storico, in: Opere varie (= Opere, Michele Barbi and Fausto Ghisalberti [eds.], Milano 1943, vol. 2), pp. 623-674; here: p. 632. 
From the perspective of the literary texts in question, Manzoni's own contribution to the genre, I promessi sposi, may be highly suitable for elucidating the reasons behind the subgenre's eminent success, the problem of its categorially hybrid basis notwithstanding. When Manzoni describes in his text-deriving his depiction from authentic historical sources from the period in questionthe beginnings of the terrible plague which hit Northern Italy during the Thirty Years War and deprived it of one third of its inhabitants, he begins by stating that the population of Lombardy was physically weakened at the moment when some soldier of the imperial army brought the bacterium to Italy. The prehistory of this condition was the failure of crops the previous year and the resultant food shortages, but above all the measures the government of the largest city in the region, Milan, had taken in order to handle the problem: the imposition of a maximum price on bread, with the-at first sight laudableintention to make bread available to everyone. The factual consequence of the decree, however, was that farmers and bakers hoarded grain instead of selling it at the price imposed by the government, because this was not sufficient to cover the costs of production. The ensuing famine then created optimal conditions for the rapid spread of the pathogen amongst the population.

The amazingly lucid analysis of the economic mechanisms at play in the city of Milan in the year 1628 reaches its decisive point when the narrator equates the situation to what happened in another place and at another time, namely in Paris during the period of la terreur: "Ci si permetta d'osservar qui di passaggio una combinazione singolare. In un paese e in un'epoca vicina, [...] si ricorse, in circostanze simili, a simili espedienti [...]" / "I allow myself here to consider in passing a remarkable constellation. In a nearby country and an epoch close to ours, [the authorities] had, in similar circumstances, recourse to similar expedients". ${ }^{503}$ Since the period the narrator is referring to is still "vicina", he does not need to explain the extent to which the two situations are parallel: as Lombardy's history was influenced for many decades by the indirect consequences of the government's mismanagement of the situation, so was France's. The discontent provoked amongst the tiers état supporters of the Revolution by the bread shortage paved the way for the thermidoriens to take over and, finally, for the "first consul", who would then become the Emperor Napoleon, to end the period of Revolution, but to start at the same time the devastating period of the Napoleonic Wars.

503 I promessi sposi, in: Tutte le opere, Alberto Chiari and Fausto Ghisalberti (eds.), Milano 1954-1974, vol. 2,1, pp. 1-673; quote: p. 477. 
The above-cited comment by the narrator of Manzoni's text lays bare a more abstract characteristic: at least in part, the subgenre of the historical novel indeed deals with particulars that actually occurred; but the way it deals with real-world, historical events-or rather, the way readers deal with such events ${ }^{504}$-is similar to the way readers deal with obviously fictional events presented in narratives. The interest is not only or not even primarily directed at the events in their concrete particularity. ${ }^{505}$ Readers are searching for the "more general", for the possibly transferable meaning of the narrated events, or, as Manzoni has it, for events "che [...] hanno fatto un simil corso"506 / "that have followed a similar course". I should stress that Manzoni's conceptualization of this "more general" level implied in the particulars of the plot targets the question of cause and effect. It is thus directly linked to the meaning of the katholou contained in Aristotle's text.

And it indeed seems to be such a process of abstraction which governs the reception of historical novels beyond the confines of the communities who would be inclined to read them, in part at least, as quasi-documentary, that is, as about "their" past. Non-British readers of the Waverley Novels (1814-1831) may take the historical background of the particular plots as a possible contribution to the "more general" question-applying almost everywhere and at various times-of how to overcome internal strife after a more or less violent merging of previously distinct political entities; readers of Flaubert's Éducation sentimentale (1869) might read the famous chapters on the events of 1848 as a "more general" claim that the historical period of revolutions is a thing of the past, and that all such current and future events are but poor, if not ridiculous imitations of 1789 (etc., etc.). In a nutshell: their being bound to specific places and times, and, thereby, to specific communities notwithstanding, historical novels may be received in the same manner as entirely fictional novels-that is, by way of abstracting from the vestiges of their "roots". ${ }^{507}$ There is nothing

504 It must be stated that not every author gives such explicit hints at a "more generalizing" way of interpreting the historical events narrated as Manzoni does in the above-quoted passages. 505 The alternative implied in this statement may characterize the attitude of "national" readers on the one hand and that of "international" readers on the other.

506 I promessi sposi, p. 542.

507 It would by far exceed the limits established for this book were I to continue this line of reasoning and begin discussing how we are used to receiving authentic historiographical works. I shall leave it at saying that, at least as far as narrative (in contrast to chronicle-style) historiography is concerned, we mostly read it in a manner comparable to the way we read historical novels, and also (entirely) fictional novels. In the case of historiographical works proper, however, we usually pay far more attention to the literal level-that is, to the portrayal of the "real" events narrated-before we proceed to a symbolic or allegorical interpretation; in 
contained in them that would in principle resist their being absorbed by the universal cultural net and thus becoming productive beyond the confines of the communities whose crucial "national" events they respectively thematize.

As expressed at the beginning of this section, hermeneutical problems of this kind do not stand at the center of this book; but it should be evident that the specific way readers deal with texts they know to be "literary" is representative of the boundary-transcending tendencies that derive from the specific "ontology" that may be ascribed to cultural artifacts in general. As has been theorized by Jan Mukařovský, the de-pragmatizing approach readers automatically adopt when reading literary texts is a potentiality for other cultural products as well. ${ }^{508}$ Mukařovský, who is a neo-Kantian, labels this attitude "aestheticizing"; he emphasizes that such an approach to architecture, or even to products of daily life (pottery, clothes), privileges the internal formal organization of the specific object under scrutiny. It is particularly in this respect that I should like to point out a major difference between the aestheticizing re-functionalization of pragmatic artifacts and the way we are used to receiving literary texts: in the latter case, it need not only be the level of formal features to which we dedicate our attention at the moment when we decide to discard the reference to any specific "real" context; it may also be-or rather: in most cases it is primarily-the level of "general" meaning in the sense of abstract and thus transferable concepts to which we pay attention.

5.-As a conclusion to these deliberations concerning the status of literary topography, I should like to present some remarks on how to conceptualize the concrete phenomenon I took as a starting point, the nineteenth-century realist novel, in terms of a network theory of cultural production, by adding some lines of thought to my above explanations. ${ }^{509}$ Why is it that we find, beginning in the first decades of that century, a "new" narrative genre which is distinguished not least by a propensity for topographical description unknown in all of previous literary history, Western as well as non-Western?

As Karlheinz Stierle has shown in a seminal article on the section of Baudelaire's Fleurs du mal entitled "Tableaux parisiens", the techniques of topogra-

that sense, the reading differs from the modus legendi in the case of fiction. Yet I would guess that no reader receives a historical account dealing with, say, the history of WWII exclusively with regard to the specific events narrated. More or less inevitably, he or she will ponder the question of how such large-scale disasters can be prevented in our times, or (on an even more abstract level) of what they might impart as regards the invariable nature of human beings. 508 See Aesthetic Function, Norm and Value as Social Facts, Mark E. Suino (tr.), Ann Arbor, MI 1979.

509 See pp. 230-232. 
phical description which are to be found in nineteenth-century literary texts were extracted, according to the terminology I have introduced here, from a pragmatic genre circulating in the net, namely the genre known as Tableau de Paris (1781) established by Louis-Sébastien Mercier. ${ }^{510}$ Mercier's text is a mixture of what one could call a "travel-guide description" with a "flaneur description", the latter component being focused on unusual but noteworthy details of everyday Parisian life. Balzac's description of the quartier latin in the first pages of his Père Goriot (1835), for instance, is clearly an imitation of descriptive techniques to be found in Mercier's manual ${ }^{511}$-which was a great success on the literary market at the time. This, of course, raises the question of why there was suddenly a demand for a description of Parisian sceneries that was modeled in principle on the genre of city-epideixis, existing since antiquity, ${ }^{512}$ but much more detailed and much less laudatory in nature, instead foregrounding “interesting” places, objects, and people.

This shift in demand may be linked to another factor of importance with respect to the emergence of literary realism which, in principle, has already been investigated by scholarly specialists for a long time: ${ }^{513}$ when Balzac calls his novels drames (as he frequently does), ${ }^{514}$ he is referring to a generic label introduced by Denis Diderot in his reflections concerning the problem of how a tragedy adapted to modern times might best be conceived. In the Entretiens

510 "Baudelaire and the Tradition of the Tableau de Paris", New Literary History vol. 11/1980, pp. 345-361. The basic assumption underlying my argument is, of course, that France was first in creating literary realism. This will go uncontested as to Italian, Spanish, German, Scandinavian, Russian (etc.) literature. Is it too daring to advance the thesis that Dickens might have been inspired by texts created immediately beforehand by Balzac? If this is not the case, one might consider a sort of direct line from Richardson to Dickens in the English tradition. Be that as it may, it needs to be stressed once again that the Brits' insistence on their "insularity" is, at least as far as high culture and its products are concerned, one of the many myths created primarily for political purposes. Cultural transfer between Britain and continental Europe, especially France and Germany, has always been extremely intense.

511 Regarding this point, including remarks on topographical descriptions in Le Colonel Chabert (1832) and Eugénie Grandet (1833), see my Balzac und der 'Effet de reel', pp. 109-115.

512 For a convenient overview of the genre's history from Greco-Roman times onward, see the first chap. of Jeffrey S. Ruth, Urban Honor in Spain: The Laus Urbis from Antiquity Through Humanism, Lewiston, NY 2011.

513 See H. R. Jauss, "Diderots Paradox über das Schauspiel (Entretiens sur 'Le Fils naturel')", Germanisch-Romanische Monatsschrift vol. 42 / 1961, pp. 380-413; see also my Ästhetik der Wirklichkeitsdarstellung, chaps. I-IV (pp. 6-100).

514 Most famously, perhaps, in the narrator's characterization of the plot of Le Père Goriot: “Ah! sachez-le: ce drame n'est ni une fiction, ni un roman. All is true, il est si véritable que chacun peut en reconnaître les éléments chez soi [...]” (p. 848). 
sur 'Le Fils naturel' (1757) and in the Discours sur la poésie dramatique (1758), Diderot adopts the Aristotelian argument that the purpose of drama is to arouse emotions in the audience. His concept of "emotions" is, however, much broader than in the case of the Aristotelian reduction to phobos and eleos; it also comprises less intense affects such as sympathy and empathy. But Diderot's most important argument for the creation of a substitute for the, according to him, obsolete genre of tragedy is linked to the specific recipients he has in mind: why should the emotions of late eighteenth-century middle-class Parisians be aroused by scenes from a world so different from their own, a world of princes and kings which the Enlightenment had taught them to regard skeptically, if not with downright hostility? Some decades later, it was FrançoisRené de Chateaubriand-a political reactionary-who produced the most impressive characterization of this shift in literary demand linked to a shift in the nature of the audience itself, which in turn reflected a political evolution, the abolition of the feudal system: “Avant la Révolution, on n'interrogeait les manuscrits que relativement aux prêtres, aux nobles et aux rois. Nous ne nous enquérons que de ce qui regarde les peuples et les transformations sociales". ${ }^{515}$

Diderot, for his part, invested his energy in speculating as to what might be the best way to arouse emotions in the new kind of audience when presenting dramatic plots based no longer on the fates of royalty and aristocrats, but instead on the life of the bourgeoisie. ${ }^{516}$ Is it possible to feel as deeply shocked

515 "Préface" to the Études historiques (1831), in: Chateaubriand, Euvres complètes, Paris 1861, vol. 9, pp. 5-99; quote: p. 29.

516 I would like to stress that I am here referring to another strand of Diderot's reflections concerning a "new" drama than the one already discussed above (pp. 230-232). It might be confusing that in the previously discussed argument by the philosopher, the term and concept of tableau plays a major role, as is the case in the context here expounded, where the term as such is not Diderot's, but is rather linked to the "new" genre created by Mercier. When Diderot talks about the tableau as a means of enhancing emotionalization, he has in mind scenes on stage-as I tried to put it by recourse to the dichotomy introduced by Fried-that are no longer theatrical, but "self-absorbed". Balzac obviously received this argument and adapted it to the frame of narrative text, where instances of spectators "seeing" something can only be intrafictional. In one of his earliest masterpieces, Le Colonel Chabert, the "widow" of a Napoleonic general who has since married a man of the old high aristocracy has to figure out how to deal with a somewhat problematic situation when her supposedly dead first husband suddenly appears in Restoration Paris. She finally succeeds in making him renounce his real identity and thus stay "dead" by arranging a scene in which she exchanges motherly caresses with her two young children and complains that the innocent kids' happiness will soon come to a cruel end, while feigning that the entire scene has not been prearranged by her. She thus creates a "self-absorbed", emotionally convincing situation-with her former husband as the targeted spectator-which is explicitly labeled by the narrator as a tableau ("Les mains [des deux en- 
by the vicissitudes of the fortune of a humble "père de famille"517 as in the case of a king whose horrible, but unconscious past mistakes lead the entire polis into destabilization and disaster? Diderot's answer, once again, draws on basic arguments found in the Poetics, while, once again, changing the emphases of the argument in question. Aristotle holds-though somewhat in passing-that there is a prerequisite for empathy, namely, the possibility on the recipients' part to consider themselves as homoion, ${ }^{518}$ that is, equal or similar to the tragic hero. It seems that in Aristotle this clause is mainly meant to refer to the psychic and intellectual profile of the hero, and not primarily to his social status. This said, the "democratic" Athens of the fifth century BCE was structured in a way which differs dramatically from eighteenth-century Europe. The audience attending performances of plays like Oedipus Rex consisted mainly of adult full citizens, who represented not more than roughly $10 \%$ of the population. According to a terminology familiar from early modern and modern times, the audience of the classical Greek tragedy performances was aristocratic. ${ }^{519}$ There was indeed a certain distance between their real-world situations and the settings represented on stage, but it was not unbridgeable, at least not in terms of imaginary identification.

Things were dramatically different in Europe in the Age of Absolutism. The lifeworld of bourgeois (tiers état) people was so far removed from that of the court that emotional identification might have been a difficult thing; and the closer one comes to the actual Revolution of 1789, the more there might have been a conscious unwillingness, on the part of the tiers état, to identify with the stage analogues of people whom they considered to be oppressors and decadent profligates. Consequently, Diderot proposes that the genre of dramethat is, modern-style tragedy-should present "dramatic" scenes of bourgeois life. Still, there is the question of how to reach a level of identification that is sufficient to provoke empathy. Is everyday misery (looming bankruptcy; the

fants] étaient étendues vers la mère, et les deux voix enfantines se mêlaient. Ce fut un tableau soudain et délicieux ! [...]”; Le Colonel Chabert, Pierre Citron [ed.], Paris 1961, p. 123). In the case of the argument discussed above, it is rather Mercier's concept of tableau which is at stake, that is, detailed topographic description. With regard to this acceptation of the term, Diderot did not produce the concept as such, but rather theorized the reasons for its integration into the repertoire of the emerging realist novel: tableau-style description may yield a "reality effect", albeit one that has a profile different from the device of onstage tableau.

517 This being the title of one of Diderot's drames, created in 1758.

518 Poetics, chap. 13, 1453a 4-6 (see also chap. 15, 1454a 24).

519 See also the more differentiated assessment of the Athenian audience of classical times above, pp. $158 \mathrm{f}$. 
pregnancy of an unmarried daughter $)^{520}$ apt to provoke emotions in the audience, especially if they are aware of the fact that the concrete configuration is fictional? Diderot's answer to the question is inspired by a device he extracts from the net, namely, from the novels of Samuel Richardson. ${ }^{521}$ Without disclosing to his readers the rationale behind this technique, Richardson endows his novels-particularly Pamela (1740) and Clarissa (1748)-with what is, according to Diderot, a distinctive feature: "une multitude de petites choses [auxquelles] tient l'illusion; il y a bien de la difficulté à les imaginer". ${ }^{522}$ The effect of all these-at first sight contingent, that is, meaningless-details is, according to Diderot, the impression on the recipients' part that the entire action is not something invented, something fictional, but rather something real. ${ }^{523}$ It is no longer the immensity of catastrophe that provides the basis for the recipients' emotional arousal, but the "reality effect", the conviction that "all [this] is true" (to quote from Balzac's Le Père Goriot), ${ }^{524}$ that provides the emotional engagement which is a prerequisite for the readers' positive response to the text.

To summarize: it seems that literary realism's most conspicuous device, the accentuation of topography, owes its "origins" to a shift in the recipients of literary products that occurred in the eighteenth century, especially in the prerevolutionary second half. The bourgeois class-whose members had achieved a high degree of literacy-constituted the principal consumers of books in the emerging literary market. These new readers did not find the traditional genre of classical tragedy relevant to their middle-class lives, so different from the milieu of the classics, and thus impossible for them to empathize with. The "new" genre of drame, proposed by Diderot as an adequate substitute, is, according to him, a combination of tragedy and comedy; ${ }^{525}$ from comedy, it takes the setting of everyday bourgeois life; from tragedy, it takes the element of calamity befalling the principal personages. The question of identification on the recipients' part-provided for within the reception process of classical tragedies by the narcissistically fueled imaginary "bridging" of the gap between kings and an aristocratic audience-is resolved by "lowering" the impression

520 I am referring not only to Diderot's, but also to Mercier's contributions to the new genre. 521 As to his Éloge de Richardson (1762), see Ästhetik der Wirklichkeitsdarstellung, pp. 13-55. 522 Éloge de Richardson, in: Euvres esthétiques, pp. 29-48; quote: p. 35.

523 Let me add in parenthesis that Roland Barthes built his theory of literary realism as developed in his famous essay "L'Effet de réel" on this argument first advanced by Diderot (first print in Communications vol. 11/1968, pp. 84-89).

524 See the reference given in n. 514.

525 See Entretiens sur 'Le Fils naturel'; as to the description of the genre of drame, see specifically pp. 137-140. 
of fictionality and by increasing the level of alleged "reality"; this (amongst other devices ${ }^{526}$ ) should be achieved, according to Diderot, by way of creating reality effects based on an accumulation of descriptive details without an obvious function in the narrative as a whole. This "new" technique, to be found in a somewhat embryonic stage in Richardson, only became systematically implemented starting with Balzac, who extracted the specific descriptive techniques from a pragmatic genre already circulating in the net, the Mercier-style Tableau de Paris, which, while being based on the classical genre of "praise of one's city (of birth)", distinguishes itself from its model by focusing on the "interesting", that is, the "curious" features of present-day city life, thus catering to the needs of a new readership who, on behalf of its social position, is no longer interested in questions of origin and provenance, but rather looking for a presentation of the "real" world as a scene or a stage, a mentality that later on became the basis of middle-class tourism.-As a result of these processes of extraction from the net, recombination, and refunctionalization, there emerges, finally, the new genre of the realist novel with its accent on literary topography.

6.-A second major objection to the views expressed in my polemics against Herderian-Romantic theories might emanate from the fact, mentioned in passing on various occasions but not yet discussed in detail, that literary artifacts are by necessity bound to one specific language-meaning, to an arbitrary code that only "works" within certain ethno-geographic and historical contexts. This factor needs to be addressed at some length, all the more as literary texts are, insofar as they are not referential, bound to what is undeniably their own, namely: the way they make use of language. Isn't the particular message conveyed by a (literary) text inextricably linked to the particular language in which it was first conceived? This is the Herderian claim, maintained and developed further in Wilhelm v. Humboldt's famous essay "Über die Verschiedenheiten des menschlichen Sprachbaues" (1827-1829). ${ }^{527}$ The latter even postulates that specific worldviews ("Weltansichten") are linked to specific languages. The point at issue is of a more intricate nature than the question of "topoi"; for there is no standard process of abstracting from the language in which a text

526 I refer to my above discussion of another device recommended by Diderot, the onstage tableau, whose functional dimension consists, in the final analysis, in providing emotionalization, mediated by the recipients' impression that what they are viewing is a "real" (and not an arranged) scene (pp. 230-232).

527 On Language: On the Diversity of Human Language Construction and Its Influence on the Mental Development of the Human Species, Michael Losonsky (ed.), Peter Heath (tr.), Cambridge, MA 1999. 
is written during the process of reception; or, to put it more adequately, perhaps: even if one abstracts from the specific acoustic or graphic units by which concepts are conveyed in the process of listening or reading, these-including their "musical" and above all their associative potential-remain present in the recipient's mind.

Yet, as evidenced by the practice of translation not only of pragmatic, but also of literary texts, including poetry, there seems to be the possibility of such a process of abstraction in the case of language, too. The price to be paid for the "loss" of the original acoustic and associative dimensions needs to be discussed; but dismissing translations of literary artifacts as "poor" in principle, or as makeshift solutions only for the uncultured who have not mastered several foreign languages, seems to be a position which neglects many prominent cases testifying to the fact that translations, as "inadequate" as they might be, may attain a high relevance in terms of literary evolution and dynamics. One might think of the influence of the "German Shakespeare" from the age of Romanticism onward, of the extensive reception of English and German translations of Baudelaire's Fleurs du mal (1857), of various Western European translations of works originally written in Scandinavian or Slavic languages, etc.

Before I come to deal with the question of the "quality" of translations, I should like to stress that my general theoretical postulate-that culture evolves in virtual circuits and networks that are in principle not restricted by linguistic, political, or mores-bound frontiers-would not even be affected by the finding that translation is always "inadequate", since my framework rejects the assumption that a literary text is reducible to the "intentional formation" 528 it might have expressed when it was conceived by its author. And it also rejects the assumption that a literary text's "essence" consists in its "identitarian" reduction within the (ethno-linguistic) community from which it emerged. ${ }^{529}$ The floating-in-the-virtual-net of a given work is a process that is factual without regard for the intentions of those who give "birth" to the works in question. In very many cases-the most prominent one in cultural history might be the circulation of the text commonly known as the Bible beyond linguistic and cultural borders-processes of floating-in-the-net involve distortions if considered from the standpoint of the "original" document. ${ }^{530}$ But culture is primarily

528 The term was coined by Roman Ingarden, The Literary Work of Art: An Investigation of the Borderlines of Ontology, Logic, and Theory of Language, George G. Grabowicz (tr.), Evanston, IL 1974, p. 366.

529 I am thinking, e.g., of I promessi sposi as a first manifestation of an Italian "national" identity-this is to date the current reading of the text in Italy.

530 I should like to emphasize that I have consciously avoided having recourse to the perhaps most expedient device for fending off possible objections to my conceptualization of the status 
an enterprise consisting in re-appropriations of pre-existing material. The main question is not the one of "loyalty" to a supposed original, it is the one of intellectual and artistic productivity. ${ }^{531}$ This applies all the more if we move, once again, from the perspective of production to that of reception. Recipients who are not able to compare the translation with the original (as is the case with me when I read, for example, Henrik Ibsen) are not able to register the "loss" that goes along, almost inevitably, with translation. And even if there are dimensions which elude translation, processes of circulation beyond linguistic borders may produce "new" and interesting constellations completely alien to the original. Within the virtual network of culture, there is no dichotomy of right vs. wrong reception; it is superseded by the dichotomy of productive vs. non-productive reception.

This said, there are many more adequate renderings of texts beyond linguistic borders than the assumptions prevalent in an academic world that continues to be bound to basic concepts of Romanticism allow scholars to concede. On the other hand, there is no denying that Madame Bovary in French is different

of the original language in which a literary work of art is written, namely, the reference to Walter Benjamin's well-known essay "The Task of the Translator". Benjamin, here as elsewhere in his writings, is indebted to the speculative philosophy of German Idealism and to the aesthetic theory of the early Romantics: if there is one "true" language which is no longer accessible to us on behalf of the process of rationalization, (good) translations might add further fragments to the fragment of truth that is contained in the original text and thus help readers gain a sort of pre-linguistic intuition ("eine Ahnung") of the truth as such. From such a perspective, translations are in principle a "good" thing (quite as they are in principle a "bad" thing from the standpoint of a Herderian approach). My suggestions are equidistant from both of these, in my view similarly exaggerated, positions. Of course, a work of art "loses" something when it is translated into another language; but it may be an all too enthusiastic speculation that the work at stake should also automatically "gain" something by way of the same process. The essential point is whether translations impede or enlarge a given text's cultural impact beyond the confines of its original tongue. From such a perspective, it is less the question of translation as such that seems crucial than the question of the quality of a given translation. It is, of course, conceivable to reduce Madame Bovary, by way of a negligent and hasty translation, to the level of one of the trivial love stories Emma indulges in reading when she is a pupil in a convent. But in the case of translation as practiced in Europe and beyond for centuries now, such primitivizations are absolute exceptions. If translations are done carefully, they succeed in preserving, if certainly not the original, its level of sophistication (once again, lyrical poetry may be a separate case), even if there is partial "misunderstanding" or a reduction of complexity involved. It belongs to the paradoxes of what we call "culture" that such relative primitivizations may have productive effects with regard not to the singular work in question and its understanding, but to cultural production in general (see, once again, my remarks on Petrarch's "reductive" translation of Boccaccio's story of Griselda, pp. 142f.).

531 -which also means that not all reworkings of a pre-existing text are valuable. 
from Madame Bovary translated into English, German, or Russian. As already said with regard to the respective heroines of Flaubert's and Fontane's most famous novels, there is, mutatis mutandis, a difference in atmosphere also with respect to language. Almost automatically, a reader links a text written in French to other texts written in that language that are known to her or himthat is, to "French culture"-whereas the systematic character of arbitrary codes makes it almost impossible not to link a text that has been translated from French into German to other texts written in German-and thus to "German culture". Since the references to "real" places are typically not altered in translation, ${ }^{532}$ there are, conversely, certain barriers that prevent the total absorption of a translated text into the culture of the language into which it has been translated. Still, and as may be extrapolated from my above remarks on drama and topographical description, the scarcity of such barriers in the case of theater might be conducive to a total absorption. Perchance it is not entirely contingent that it was an English dramatist rather than an English novelist who was adopted by German culture to such an extent that he became part of the imaginary German cultural heritage.

In the following, I should like to make two points of different levels of abstraction in order to illustrate my position: the fact that literary texts are (initially) bound to one specific language does not yield a sufficient basis for rejecting the view that the concept of "national literatures" is mainly an ideological one whose functional context is above all political.

7.-The first point I should like to adduce in this respect concerns the historical nature of natural languages. Highly cultured present-day speakers of French may be able to read the Chanson de Roland (ca. 1100) without much additional aid or instruction; average readers would capitulate before this task. Things are even more difficult in the case of a text like the Nibelungenlied (ca. 1200). Apart from professional medievalists, even educated present-day speakers of German would not be able to grasp more than the bare outline of the text. As to the British "national" epic, Beowulf (ca. 700), ${ }^{53}$ no one who has not been previously trained will be able to understand much of anything from the text if confronted with the original version. To restate this on an abstract level: the supposedly "natural" link between texts from a specific "national" tradition and readers from that same nation is subverted by the continuous historical

532 An English (or any other) translation of Madame Bovary also stages the action in Normandy, that is, in France.

533 As to the dates in brackets, I ask possible readers who are medievalists for their benign indulgence (while stressing that this book does not belong to the Medievalia). 
evolution of natural languages. This may (and frequently does) cause such a degree of difference between the current language and its earlier stages as will render older texts incomprehensible to present-day readers even though they may originate from "their" ancestors-and this to an extent that does not systematically differ from the incomprehensibility of "foreign" texts. For a present-day speaker of English, it does not matter whether she or he is asked to summarize a text written in Old English or in contemporary Norwegian; she or he will not be able to perform the task. ${ }^{534}$ The assumption that readers have a "natural" (non-mediated) access to any texts composed in the same region where they were born is a perspectival illusion produced by the fact that, in the case of contemporary texts and readers, the mediatedness of the semiotic process is not apparent, due to automatization. Since verbal communication of any kind is bound to arbitrary systems of encoding, there is in principle no obstacle to an in-depth decoding of the texts in question by recipients who started mastering the respective linguistic code at a later age than those who acquired it as children.

8.-Different languages open up, however, diverse possibilities of encoding, of modeling the world. Even within so-called "language families" such as that of the Indo-European vernaculars, there are certain terms that seem to be linked to specific linguistic contexts to the extent that speakers who are able to make use of a variety of such contexts preserve these terms in their original formulation, integrating them as they are into their primary language. ${ }^{535}$ The dichotomy of eros and agape-whose blurring in the vernacular terms of love, amour, Liebe, etc. is of crucial relevance to Western literary and art history-is difficult to reproduce in modern European languages; the feeling of ennui-widespread amongst modern artists and intellectuals-seems to be untranslatable; for very good reasons, Freud rejected the vernacular term Seele ("soul”) when theorizing his ideas on the human mind, instead having recourse to the Greek term psyche, which, indeed, has a conceptual profile and an associative potential differing considerably from that of the standard vernacular renderings. It need not be stressed that, quantitatively as well as qualitatively, such problems of "untranslatability" are much more significant if one proceeds to a comparison of linguistic codes that are systematically very different from one another, such as English and Arabic or French and Chinese. (Literary) texts may be translated

534 - unless, of course, she or he is a specialist of medieval English language and literature, or a scholar of Scandinavian languages and literatures.

535 I set aside the question of further functional dimensions of a limited macaronism, such as the potential for social distinction or the effect of "dignification" as described by Aristotle in the lexis chapters of the Poetics. 
from one such language into another, as is evidenced by a long-standing practice; but in order to grasp what the original text is intended to convey, a reader not familiar with its language needs more than just a translation. In addition, she or he will require an erudite commentary on the specific conceptual profile and associative potential of this or that term in the original version.

In principle, my main argument for the refutation of the necessity of concepts such as "national literatures", supposedly emanating from the diversity of the conceptual profiles of various vernaculars, has already been articulated. A "national" or "ethnic" (tribal) belonging-having been raised within one specific cultural community-does not preclude the acquisition of foreign linguistic codes and of the cultural systems linked to them. The mastery of a consciously acquired language may indeed reach a level that is judged by its regular (native) speakers as outstanding. Samuel Beckett's texts in French as well as Vladimir Nabokov's and Joseph Conrad's texts in English may be among the most illustrative examples from recent literary history. In the contemporary globalized world, there are a great number of even more "exotic" examples of the same phenomenon: well-known writers whose mother tongue is Turkish writing in German; Iranians and Americans writing in Chinese; Chinese or Japanese authors writing in English; a Japanese-American writing a fantastical historical novel about a twentieth-century world not governed by Western people, but rather by descendants of the Aztecs, etc., etc. And there are also more modest stages of such a "xenology", as I would perhaps name it: that is, people like this book's presumed readers, cultured Westerners born in the second half of the twentieth century who do not have difficulties reading sophisticated texts written in languages such as French, Spanish, Italian, English, German, or Russian-for the simple reason that, in the course of their adult lives, they have acquired a passive mastery of several of these linguistic systems, in addition to the knowledge of a quantitatively considerable text corpus in the languages in question, which allows them to acquire a sense of the associative potentials of certain terms and formulations, and also a certain familiarity with the cultures-the social codes, the history, the traditions-of these specific linguistic communities.

It will remain an unanswerable question, however, whether the reading of $\mathrm{Ma}$ dame Bovary by a person whose mother tongue is English or German has the potential to become indistinguishable from a reading by an "autochthonous" speaker of French; or, to rephrase this as a more sophisticated question, whether the differences in reading that emerge amongst readers from different linguistic backgrounds are any more significant than differences emerging amongst readers from a homogeneous linguistic background who differ with 
respect to other parameters governing semiotic processes (gender, social class, generation, educational background, temperament, etc., etc.).

9.-Yet what about an item as important as sound-what about the "musical" qualities of literature within such a framework? Even if the texts in question are not actually performed or read aloud, recipients are conscious of the acoustic dimension of language as such-and in the case of artistically functionalized language, of literary texts, they are even trained to pay attention to this level. A novel by Flaubert does, indeed, "sound" different in the original language, French, than in English or German, let alone in Arabic or Mandarin. Still, if French has a reputation as a particularly harmonious and acoustically elegant language, would a native speaker of, say, German or Dutch who is familiar with the French original judge a well-executed translation into his native vernacular to be a repugnant demonstration of his mother tongue's acoustic ugliness? In every language, there are registers prone to produce the impression of harmony and others prone to produce the opposite effect; regarding euphony, the transposition of a literary work of art into another language is acceptable without any restrictions in case the acoustic registers of the original ${ }^{536}$ are preserved in the translation.

I am even inclined to extend this postulate to the entire level of what we are used to calling style. As to wording, it is not the fact that Flaubert's text is written in French that makes it unique; it is rather the way Flaubert makes use of French. And if "style" is characterized by the systematic choice a text makes from all the choices possible within a given linguistic system, this relation as such is transferable from one vernacular to another. Current characterizations of style such as the classical triad of humilis, mediocris, and sublimis, as well as more concrete features such as "concision", "verbosity", "transparency", “obscurity”, "metaphoricalness”, "plainness”, etc., are always meant to describe not essences, but rather relations between a standard usage of the linguistic patterns of a specific language and various deviations from this standard. This even applies to the "social" styles (sociolects) which frequently seem to be linked to literary texts from specific linguistic communities. The fundamental linguistic difference between Racinean and Shakespearean tragedy does not lie in the alleged fact that the former plays are "typically French" whereas the latter are "typically British". The linguistic code is, indeed, French in the first case and English in the second. But the difference of style can only

536 Meaning: not necessarily the original sounds and their composition. 
be captured by the opposition courtly/refined vs. popular/mixed, ${ }^{537}$ that is, by relational terms describing configurations which might exist in either linguistic community.-A certain question raised by this argument-namely, whether there may be distinctions between "national” literary cultures resulting from the respective privileging of specific stylistic constellations-will be discussed in detail below.

10.-Yet there is an additional point to be taken into consideration which is located on a level of linguistic specificity even more basic than style: it would be problematic to deny that there is an associative potential of language linked to the level of sound. Only a person capable of reading French, or another language deriving from Latin, will be able to grasp the allusion to cattle (bovis in Latin, boeuf in French, with the adjective bovin) encoded in the name of "Bovary", along with the ensuing subtext: namely, that Emma's husband is more of a dull animal than a full human being-meaning, a person without any refinement and subtlety and, consequently, someone who is not suited to the task of fulfilling the young wife's vaguely romantic aspirations. One could argue that the entire plot is, in a way, foreshadowed as soon as the recipient learns that young Emma will be married to a man named "Bovary"; this effect will materialize, however, only in the case of the text's reception in its original language, not in translation. ${ }^{538}$ Since "internal (over-)structuring" seems to be a distinctive feature of literary texts in contrast to pragmatic texts, is it tenable, given constellations such as the one briefly characterized here, to regard the link between (literary) text and (original) wording as not being of primary importance?

It is evident that this problem is particularly relevant when it comes to that genre for which the level of plot, if there is any at all, is characterized by an extremely high degree of standardization, whereas the important, original level is the one of formulation, including sound-that is to say, for the genre of poetry. It is for this reason that rendering poetry in translation is believed to be difficult or even impossible. Even so, it can hardly be denied that there is a reception history of poetry in translation. It is far from an exaggeration to say that the only poem by Sappho that has come down to us in its entirety, the socalled Fragment 1-or rather its circulation in the net for more than two and a

537 In the sense of Erich Auerbach's famous thesis that literary realism is characterized by a free mixing of the three (distinct) levels of style as theorized in ancient rhetoric (Mimesis: The Representation of Reality in Western Literature, Willard R. Trask [tr.], Princeton, NJ 2013).

538 -or only with respect to readers who are in principle able to read the original as well and may thus realize what the "untranslatable" proper name implies. 
half millenia by now-is the origin of and main inspiration for the vast and multifaceted corpus of (Western) love lyrics, and this despite the fact that most readers and poets have been, and continue to be, unable to read it in its original form.

To put my point in more abstract terms: The level of sound is not negligible. But if one provisionally sets aside high modernist attempts to reduce poetry to sound and bring it close to music, ${ }^{539}$ one might hypothesize that sound is one among a (literary) work of art's many parameters, the workings of which cannot be theorized in a generalized way with regard to processes of reception. The extent to which a recipient makes use of the level of sound and allows this dimension to influence the direction of his or her inspirations is highly idiosyncratic. It is not primarily based on the question of whether the text at issue is written in the recipient's mother tongue or not. Differences between the associations perceived by two different French readers of Madame Bovary (different with regard to age, social class, individual life experience, degree of aesthetic sensibility, etc.) may be greater than those between a French and a German reader who share such or similar traits. The same applies to all non-standardized items accompanying processes of communication: to the "calligraphic" dimension of print, the "tactile" qualities of paper, the "acoustic" qualities of the voice of a performer, the "olfactory" dimension of the setting, the degree of focused attention a given recipient is able or willing to invest in a concrete act of reception, the recipient's level of cultivation, his or her immediately preceding artistic or real-world experiences-all of these are individual dimensions of the reception of a work of art. They are legitimate dimensions, especially for the reason that the work in question is received as art, that is, without referring immediately to any pragmatic context. Even so, these dimensions elude systematization. They are essential within any particular act of reception. Yet the concrete shape they assume is not bound to one specific language. It is rather bound to a specific act of reception in its fundamental singularity and non-iterability. The multiplicity of such factors is mainly an indicator of the limits of systematization that go along with all receptions of works of art.

539 Even texts which are untranslatable in the literal sense since they systematically transgress the rules governing the language-system they are based on are not, for that reason, excluded from floating beyond linguistic borders. The attempt at "translating" such texts will consider the logic underlying the specific acts of linguistic transgression (fragmentations of words and subsequent reassemblies of elementary units that are distinct in standard usage; systematic avoidance or replacement of certain letters, etc., etc.) and try to apply it to another language; even if the language of origin and the language of translation are very diverse in terms of basic grammatical concepts (Indo-European; Mandarin), a skilled translator will succeed in conveying to foreign readers the principles of wording of the original text. 
11. - If one engages in a discussion of the question of which generalizing categories one might reasonably conceive in order to describe the immense quantities of literary texts the entire species has produced to date, ${ }^{540}$ concepts like that of "national literatures" seem to be problematic in that they tacitly reduce literary texts to the functional dimension that might have been at the basis of their creation while neglecting their exogenous components as well as their potential appeal to exogenous recipients. The impression of "adequacy" which such concepts may produce at first sight is tailored to spheres which are not identical with, or even far removed from, literature and art: political discourses, identity discourses, nationalistic dichotomization, and the subsequent essentialization of entities that are highly fluid with regard to space and time.

The overall argument presented in this chapter may be put in a nutshell by recalling the basic insight of modern linguistics: languages are arbitrary systems-nothing "natural" inheres in them. Like all arbitrary or artificial things, they may be appropriated by any member of the species, and their configuration as systems-which is the enabling structure of their semiotic potential-allows for the transfer of any specific constellation from one such system to another.

\section{“National” Styles? "Hybridity"? "Third Spaces"?}

0.-Apart from the spatio-topographical specificity assignable to many literary works on behalf of the referential components they contain, apart from the linguistic specificity assignable to them on behalf of the vernacular they make use of in order to express "themselves", there is a third, in a way intermediate component typically ascribed to works of art by means of which the advocates of a Herderian approach try to substantiate the claim that there are essential differences between artworks of diverse "national" provenance, namely, the assumption of different "national styles". I shall address this point by taking a look at the (literary) culture of Europe which most insists on its "exceptional" status, namely, that of France.

1.-What does "style" mean in this context? It is certainly a category much broader than the one indicated by the proper acceptation of the term, that is, broader than actual wording, formulation, and phrasing; however, as literary artifacts consist of nothing but words, "style" in the broader sense, too, is inextricably linked to the level of actual formulation. Yet in particular when we try

540 -and we are only talking here about the fraction that has been preserved until our times. 
to describe so-called "great works", we almost always take such works to be characterized by a high degree of internal coherence not only on the level of choice of words and their concatenation, but also on that of a more general impression of compelling unity. The level of abstraction on which we locate this unity varies historically. In high modernist art in particular, it is frequently not to be found on the level of the formal organization of the artifact itself, but rather on that of an abstract concept that informs the at times quite erratic actual structure of the work. But it seems hardly convincing to talk about a given artifact as a "great" work if one is not able to ascribe to it a superior degree of internal cohesion. Works of art are not measured by their capacity to convey an adequate image of reality-this being a standard of quality that applies to many pragmatic texts-but are rather assessed according to their capacity to impress even though their recipients know that the works are devoid of any direct practical use-value. What else could lastingly impress recipients if not the work's subtlety of internal organization? There may be further factors (for instance, the potential to connect to other great works, artistic or nonartistic, of the period and thus to contribute to constituting a more comprehensive internally coherent unity we tend to call an "age" or "epoch"), but the item mentioned seems indispensable..$^{541}$

2.-I would like to link my speculations concerning the question at issue to my above deliberations on early modern drama: many of the differences observable between various "national" traditions of drama may be contingent on different principles of establishing internal unity; but it remains to be discussed to what extent such differing principles of coherence can be convincingly linked to particular national communities. ${ }^{542}$

541 In order to avoid misunderstandings: the argumentation in the above passage is not contrary to my frequently quoted point of reference with regard to the function of receiving literary texts, namely Freud's essay “The Relation of the Poet to Day-Dreaming”. Here, I am dealing not with questions of function, but rather with the problem of relative preference for one work over others, that is, with the dimension that provokes, according to Freud, what he calls "Vorlust": the conscious pleasure a reader takes in reading a text (or a beholder takes in viewing a painting). This "Vorlust" is linked to the formal sophistication recipients are able to detect when receiving a work of art. Although it may be an instrument of self-deception with the aim of precluding consciousness of the "real" motives behind reading fiction, the recipient's preoccupation with formal sophistication is a factual dimension of dealing with art.

542 It is perhaps at this point in my argument that I should refer to a case study published by Stephen Greenblatt in the volume Cultural Mobility (n. 5). Greenblatt narrates an intriguing story about his idea to rewrite, with the help of a present-day American playwright, one of Shakespeare's lost dramas, namely The History of Cardenio (“Theatrical Mobility", pp. 75-95). Like many of Shakespeare's plays, this one, too, was based on a written source of non-English provenance, namely on one of the stories interpolated in Cervantes's Quijote, the English translation of whose first part (1612) had been a great success on the literary market. The Cardenio 
If one is prepared to sufficiently narrow down the temporal scope, it is striking to observe that serious French drama of the early modern age is characterized by only one verse pattern, the twelve-syllable alexandrine, whereas English drama is much more open to varying verse patterns; there is prose, there is blank verse, and there is rhymed verse. But the most "open" variant of early modern drama, at least in terms of versification, is to be found in Spain. Spanish dramas of the late sixteenth and seventeenth centuries display passages in endecasílabo (verses of eleven syllables), décimas (ten syllables), silvas (a combination of verses of eleven and seven syllables), romances (verses of sixteen syllables), and redondillas (verses of six to eight syllables), just to name the most important patterns. The uniformity of the French standard verse is echoed by a relatively restricted vocabulary, whereas English and Spanish dra-

story deals with two couples who first become separated from each other, partly due to unfavorable circumstances (that is the "Hellenistic" strand of the story), partly due to the egocentric misbehavior of one of the male protagonists. As befits the Hellenistic scheme, the ending is happy: the couples are reunited and the egotist marries the young lady to whom he once proposed, leaving the other, whom he courted in the middle section of the tale, to the man she is in love with, that is, the second male protagonist.-Since nothing is preserved of Shakespeare's play except the title, Greenblatt and his collaborator were free to reassemble the pieces they extracted from the cultural net in a way they thought productive. They boldly decided that another of Cervantes's interpolated stories, the famous El curioso impertinente (which is linked to the Cardenio story in that it is being read from a manuscript when Cardenio interrupts for a while with the account of his own past adventures), is much more suited for dramatization. The Curioso impertinente is also a story about the intricacies of love, but it reduces the scheme of four personages to a triangle consisting of a jealous husband, his best friend, and his wife. Its basic pattern is the motif of the "love test", by which the husband intends to find out, with his friend's help, whether his wife is unconditionally loyal or not; the outcome is tragic, as the wife and the friend finally do engage in an adulterous relationship; when the husband becomes aware of it, he dies, while the two adulterers fall prey to vicissitudes in which they become entangled because of bad conscience.-In the context of the present study, it is worth mentioning that, in addition to the recombination just referred to, the authors decided to substitute the original ending of the Curioso impertinente with the happy ending of the Cardenio story, that is, to cast the play as comedy (which it was, supposedly at least, in Shakespeare). Greenblatt ends his account of his career as a playwright by referring to some stage productions based on his play; the one which astonished him most took place in Japan and seems to have been a Regietheater-like alienation (in the sense of Brechtian Verfremdung) of the original play; rendered in English, the title of the Japanese production was Motorcycle Quijote. According to Greenblatt's account, it consisted of a sort of hybridization of his rewriting of Shakespeare/Cervantes with popular clichés about twentieth-century American youth culture as presented in films such as Easy Rider (1969).-The entire constellation is a sort of quasi-ideal paradigm of the primacy of what I here call the reassembly of pre-existent material when it comes to the processes of cultural production, and it also illustrates how ideas of "unity" and "coherence" shift when we consider different periods or different communities. 
mas of the time make use of the whole range of linguistic registers available, including popular and even vulgar strata. The figures acting on stage are likewise diverse when compared to the mostly homogeneous characters of French tragedy; $;^{543}$ and one could even regard the frequent feature of "gender trouble" (females disguised as males and vice versa) in English and Spanish serious plays of the time-I am not referring here to comedy proper-as a further reflection of a formal as well as content-related "openness", entirely absent in the case of the French classical tragedy.

Perhaps paradoxically, the examples briefly characterized above yield a strong counterargument to an all too complete relapse into the concepts of idealist aesthetics: ${ }^{544}$ the remarkable formal "openness" of the Spanish drama of the time is neutralized if not annihilated by its overall ideological illiberality. The texts, praised by none other than Goethe as the apogee of world literature, ${ }^{545}$ are in terms of their message most rigid instances of Tridentine Counter-Reformation propaganda. Was it the mix of ideological "closedness" and formal openness which led to the great success of these dramas throughout Europe, but only during a brief period stretching from the beginning to the middle of the nineteenth century? Shakespearean drama, which was no less successful in that age, but which continues to be enormously popular in our own times, is characterized by the rejection of closedness on all levels of the text. French tragedy, still popular in its country of origin, but no longer outside, is a paradigm of formal closedness and of maximum semantic coherence. Even if this closedness does not include, as in the case of the Spanish drama, the level of general worldview (including the afterlife), the French classicist tragedy with its specific variant of internal coherence may have lost some of its former transcultural fascination when Romanticism-which was a pan-European attitudeand its somewhat enthusiastic ideas of generalized freedom, including artistic freedom, gained the upper hand.

543 I am referring to the level of important characters only; of course, there are servants in French tragedies; but compared to their analogues in Shakespearean or in Spanish Golden Age (serious) dramas, their role is a very marginal one.

544 I am referring to the Hegelian conviction, expounded in the latter's Lectures on Aesthetics, that art is characterized by a correspondence, albeit to varying degrees, between "content" and "form".

545 It is in particular Calderón's drama on the first attempts at discovering unknown worlds, El principe constante (1628/1629) - which deals with the Portuguese expansion into Moroccothat was hailed by Goethe as a work from which one would be able to rebuild the entire system of poetry and fiction ("Poesie") if one day all literary works were lost (Letter to Schiller, January 28, 1804; in: Gedenkausgabe der Werke, Briefe und Gespräche, Ernst Beutler [ed.], Zürich 1948-1954, vol. 20, p. 964 f.). 
As to the varying logic of internal organization, there seems to be no more to be said than that a certain degree of cohesiveness is mandatory if a newly assembled artwork is to become popular instead of remaining inactive in the net. If the shaping does not attain a level sufficient to individualize the work in question-to make it distinguishable from other individualized works floating in the net-it will sooner or later be absorbed by other, similarly structured works, and go on hovering as a mere instance of a pattern or paradigm, e.g., that of the "trivial love story". But whether the principle of this individualizing formal coherence needs to be a "positive" or a "negative" one, whether it is total or rather non-total coherence which tends to pave the way towards a worldwide reception-this question shall remain unanswered here and left to my readers' own reflection. For the time being, the only means I see of grasping these historically shifting conceptualizations of coherence would be Ernst Robert Curtius's model of alternation between phases of what he calls "classicism" (a strict and pervasive concept of coherence) and "mannerism" (a much more flexible way of building coherence, in many cases just by opposing classical features). ${ }^{546}$ In addition, one should take into consideration an aspect of historical conceptualization which Karl Mannheim has called the "non-contemporaneity of the contemporaneous", ${ }^{547}$ meaning that in every epoch there are both dominant and non-dominant features, the latter being previously dominant (that is, obsolete) or precursory items. In the above, I have merely given one concrete hint at what I mean by referring to the reception of French classical tragedy since the age of Romanticism. ${ }^{548}$ But as to the questions of "why" and "why exactly at this moment" schemas of preference for this or that way of establishing unity change, I am afraid I have to leave it at the unsatisfactory reference to the contingency of historical processes.

3.-The partaking of the formal features in question in the transnational patrimony floating in the net explains the constant and at times rapid changes to which these secondary constellations are subjected, and it is in particular this incontestable feature which seems to destabilize the expediency of the category of "national style", which does seem to suggest itself when one only takes short-term scenarios of literary production into consideration. French texts from the eighteenth century are very different from those written in the seventeenth century, as are nineteenth-century texts from eighteenth-century texts.

546 See European Literature and the Middle Ages, chap. 15.

547 Regarding this point, see Mannheim's “Das Problem der Generationen”, Kölner Vierteljahreshefte für Soziologie vol. 7 / 1928, pp. 157-185 and pp. 309-330.

548 See the end of the preceding paragraph. 
It is an illusion produced by the (roughly) identical language in which all of these texts are written which may make an observer believe them to constitute a homogeneous fund. The complete transformation of the "pacific" and "provincial" orientation of the German culture of early-nineteenth-century Biedermeier into the aggressive attitude, also manifest in culture, which characterizes Germany from 1871 through 1945, as well as the reconversion to a relative provinciality from 1945 onwards, would be another example of the extremely high flexibility of these secondary determinant constellations. There is not much in the domain of culture which could be called the legitimate "property" of one specific community. ${ }^{549}$

4.-In order to round off the complex of questions discussed in the above pages, I should like to invite readers to take a brief glance at the drama that seems to represent the essence of French literature, that is, Racine's Phèdre, as well as the drama that seems to represent the essence of English literature, that is, Shakespeare's Hamlet. Measured by many of the parameters here discussed, these two texts are indeed distinct. But, as stressed by Jan Mosch in his comparative analysis of the two pieces, ${ }^{550}$ there is a strong tendency, due to our Herderian view of literary history, to overlook their commonalities. The latter begin with the fact that both dramas do not base their plots on autochthonous narratives, but rather on exogenous source material (Sophocles/Seneca; Saxo Grammaticus). Consequently, the action is not located on "home ground". These "external" commonalities comprise the fact that both texts have been as intensely received beyond the borders of their respective cultures of origin as they have been at home. ${ }^{551}$ And there are a few points with respect to the works themselves that need to be mentioned: They share the characteristic of being difficult to

549 The most striking phenomenon with regard to the entire constellation discussed in this chapter is the fact that reception processes in modern times, that is, in a period deeply marked by the concept of "national cultures", operate right from the beginning beyond the boundaries of the national cultures involved; one might think of the German reception of Shakespearean and of Spanish Golden Age drama, or of the French reception of Shakespearean drama. The remarkable fact that a foreign country's dramatic and theatrical culture may be "adopted" almost officially contests the nationalistic assumptions regarding culture that were discursively prevalent during the same period in the countries involved. The question one could raise starting from this observation is whether there is anything "national" at all about dramatic or literary texts in general, that is, of course, apart from language. Is literary culture an instrument of cultural imperialism, or is it a genuinely universal structure which combines cultural material in a form that engages basic (psychic) needs of humans as a species?

550 Moral Agency and Heteronomy in Shakespearean and Racinian Tragedy.

551 I have already addressed the problem of the differences between the two dramas as to these international reception processes (pp. $277 \mathrm{f}$.). 
assign to one of the two parties in the religious controversies so important for their age; it is not at all clear whether Shakespeare's Denmark is meant to be pre- or post-Reformation; Racine's plays, and Phèdre in particular, which were created in a "Catholic" country, are frequently associated with a Jansenist background, that is, an Augustinian or crypto-Protestant theology of grace. The action is in both cases marked by the political context of absolutism; in both plays, the concept of the theatricality of power, essential for the political formation we call absolutism, plays an eminent role. There is a multitude of shared motifs and metaphors, which one may attribute to the common ground of knowledge and to the transnational profile of pedagogy in the early modern age. Both dramas, in contrast to earlier stages of European drama, attest to the reception of Aristotle's Poetics, though with varying degrees of emphasis. Both manifest the interactional codes of courtly societies. And I shall not address here in detail the many commonalities that one might attribute to anthropological constants, e.g., the basic motif of incest; the struggle for power; the propensity for cruel violence in order to settle problematic situations (etc., etc.).-Considering all these points, I am tempted to no longer qualify Hamlet as "the most important English drama” or Phèdre as "the most eminent French drama"; I would rather suggest regarding the two pieces as the most impressive dramas from post-classical times which have come down to us, respectively, in English and in French.

5. - In view of further nuancing this argument, I would like to come back to the general concept of national culture as discussed above, while trying to differentiate my polemics from the postmodernist and postcolonial discourses that have become the mainstream in recent times. One very instructive example of these latter conceptualizations which is linked to this book's specific literary field is Friederike Pannewick's essay in the volume Cultural Mobility: A Manifesto. ${ }^{552}$ It deals with the question of an Arab theatrical culture, which, as Pannewick concedes, only emerges in proper terms during the first half of the nineteenth century, that is, concomitant to the process of Western penetration into the countries of Muslim culture. As I am no expert in the field, the claim that there has been a burgeoning "autochthonous" theater scene in the Arab world during the subsequent period shall remain uncontested here; if this is, indeed, the case, it would constitute yet another confirmation of my hypothesis regarding the mechanisms of cultural dynamics. The point to be discussed rather concerns the period before the (to put it in a neutral fashion) "transfer" of occidental theatrical culture to the Muslim world.-Everyone reading this book will be familiar with

552 "Performativity and Mobility: Middle Eastern Traditions on the Move", in: Greenblatt et al. (eds.), Cultural Mobility, pp. 215-249. 
Jorge Luis Borges's aforementioned short story dealing with the problem at stake, which is entitled La busca de Averroes. In a fictional manner, it tells of the famous Aristotelian's incomprehension regarding the argument of one of Aristotle's texts, namely, his tract on theater, the Poetics, although the rest of the philosopher's oeuvre is fully accessible to him. The reason for this incapability consists in the fact that it is impossible to "understand" concepts which do not already exist in one's own intellectual horizon. Since there was no theatrical culture in the traditional Muslim world, Averroes was not able to grasp what Aristotle wanted to convey. ${ }^{553}$

Pannewick's approach-paradigmatic of present-day scholarly discoursescontests what Borges conveys in his short story regarding theater in precolonial Muslim cultures. Her argumentation is characterized by what I have come to call the "me too" or the "we too" attitude. By referring to performative practices like the one of storytelling in front of an audience, and, in addition, to a (quantitatively) extremely limited tradition of martyr plays in Persia, Pannewick does not explicitly postulate, but rather insinuates that the assumption of the non-existence of theatrical culture in the traditional Muslim world is based on Eurocentrism, that is, the at the same time ignorant and arrogant attitude of the West towards non-Western cultures, which are thereby conceived of in terms of deficits, as less "inventive" and less productive.-In the following, I would like to make one point with respect to the argument proper and another with regard to the intention at its basis.

Pannewick is intellectually honest enough to go no further than a conceptual blurring of the boundaries between performative practices at large and theater proper; she does not explicitly deny the difference. And she provides valuable source material that is apt for explaining-from her perspective as well as from mine-the reasons why there was no theatrical culture proper in the traditional Muslim world. These reasons did not consist in a lack of cultural or intellectual inventiveness; they consisted in the fierce opposition to theatrical practices on the part of Islamic theologians. Reading the "Arab" polemics against staged performances quoted by Pannewick, ${ }^{554}$ one is instantaneously reminded of Plato's as well as of Augustine's diatribes against such cultural practices as prone to stimulate the less dignified parts of the soul-the emotions or affects-and thus to induce the spectators to act in an inappropriate way in their subsequent "real" lives. Given the fact that these Islamic tracts were written in regions not

553 This is the (according to me, highly convincing) line of argument suggested by the serene Buenairense skeptic.

554 "Performativity and Mobility”, p. 223. 
very far from or even identical to the ones where Plato and Augustine professed their views, one might be inclined to see these texts as perhaps not specifically Islamic at all. They may rather belong to a broader strand of texts inspired by the worldviews of Mediterranean monotheisms.

To summarize the first point I should like to make on a more abstract level: It would be pointless to deny that there are differences between different cultures. The question at stake is how to conceive of these differences. It is only an essentializing or, to put it in more explicit terms, a racial approach that is problematic from my perspective. But in order to evade the traps of thinking in terms of racial concepts, it is neither necessary nor sensible to level or to implicitly refute the fact of cultural difference. In the case in question, one would have to discuss in detail the reasons why the theological diatribes referred to above remained dominant in the Muslim world until the dawn of westernization while they lost the discursive battle in the Occident as early as the sixteenth century, albeit without ever disappearing-there is no blockbuster movie whose reception is not accompanied by cultural critics' voices incriminating it as "dangerous for the populace", especially for the younger generation. I cannot go into details in this respect, but will leave it at two points which should be taken into consideration: The motives behind the proclamation of the founder of the Christian religion, Jesus, that his kingdom is not of this world (John 18:36) might have been quite profane or even opportunistic. Had he articulated the opposite view, he would have been executed by the Romans even before he was able to gather a number of disciples who would carry on the divulgation of his ideas. The consequences of the utterance in question, however, were enormous as soon as Christianity was adopted by the Roman Empire and its successor states. As in the Islamic world, Christian theologians nurtured the ambition of totally controlling society, of becoming the "real" rulers. But pluralism and the ensuing reduction of religion to one functional sphere (Niklas Luhmann) amongst others is inherent in Christianity's basic doctrine. Within the dominant religion of the West, there is a (biblical) basis for rejecting the theologians' pretense to totalitarianism. In Islam, there is no such basis. Pluralization thus requires a previous secularization.

The second point I should like to suggest for a more penetrating discussion is the fact that, for whatever reason, Christianity is not a "pure" monotheism; from the standpoint of other monotheistic religions, it even appears to be a poorly veiled polytheism. When it comes to artistic production, this conceptual "impurity" might, however, bring advantages. The idea of God having become incarnate and having lived and died amongst humans makes it impossible to anathematize-as other monotheisms do-that he be imagined in the very liter- 
al sense, that is: represented. Since the Dark Ages, religious paintings and their "kinetic" variant, religious dramas (mystery plays), belonged to the cultural practices accepted or even propagated by the religious authorities. Comic interludes, that is, short profane plays (farces), were admitted, with the intention not to bore the audience with too much doctrine. As a consequence, it would have been a somewhat difficult undertaking in the Christian West to "protect" society against what was leaking out of the net when the ships bearing the manuscripts of classical dramas arrived after the Ottoman conquest of Constantinople.

6. -The example just outlined would appear in the final analysis to mean that it is religion, or worldview at large, that constitutes the basic determinant factor when it comes to the observable differences between the works assembled within different cultural communities by making use of a common fund of cultural material floating in the net. As may be evident from all I have said so far in this book, I am indeed much more inclined to emphasize the role of religion in cultural dynamics in general than most present-day research in the field, at least in Europe, typically does. But my entire approach implies that there are no such one-way determinant factors, no strict causal chains, when it comes to systematizing cultural dynamics. As important as several specific features of Christian dogma may have been for the specific formation of works of art (mainly literary texts, but also performative practices, and not least all variants of graphic art) we usually call "occidental”, the rapid spread of this religion-in its origins an unorthodox and persecuted sectarian movement within a small community under foreign rule-can only be explained by referring to contingency, a label that any reader is free to replace by that of "God", as long as she or he is conscious of leaving the section of the discursive field (champ discursif) assigned to scholarship and of entering the section assigned to faith. It was not an item of necessity that the Mediterranean world was politically organized as one massive unit, as an empire, when this sect started its attempts at propagating its somewhat unheard-of views. Without this enabling structure, a religious movement based on the ideals of "peace" and "love" (thus contrasting with another sectarian religious movement which would emerge in the same region some six hundred years later) would hardly have had the chance to extend its influence beyond the borders of the small kingdom where it originated. And it is an instance of even greater contingency (if contingencies can be quantified at all) that after three centuries of bloody persecution, the head of the state, the Roman emperor, suddenly decided to embrace this somewhat strange oriental cult and to oblige all his subjects to comply with this step.

But from that time onward-that is, for a period of at least one and a half millennia-certain parameters regarding the "assembly" of cultural material 
into single works were, indeed, more or less fixed for the region in question. Representational art (painting, theater) is in principle legitimate; the representation of "everything", including the ugly parts of reality, is legitimate, since God himself became incarnate, that is, part of this world ${ }^{555}$ narrative, the basic formal pattern of this religion's holy text, ${ }^{556}$ is legitimate; narrative clearly recognizable as fiction, that is, a strand of narrative that Plato would have liked to prohibit, is legitimate, since the religion's founder made use of the device when proselytizing, the reason for the choice of this register being evident: those he wanted to convince were primarily humble, uneducated people.-I could go on enumerating basic formal principles that distinguish, partly or totally, Western art from the artworks of other communities, but I think the examples expounded so far suffice to illustrate what I wish to express on a more abstract level: Conceiving of culture as originating from a decentralized and de-territorialized net does not imply that there are not specific features of works of art that one can legitimately link to certain regions and to certain periods. And it does not imply that it would be pointless to ponder external (that is: non-artistic) factors responsible for the evolution of art, in a specific area and period, in one particular direction rather than another equally conceivable one. But these determinant factors seem not to constitute an "ultimate ground". The factors themselves are various (political, ideological, and, as one must certainly add, economic-there may be a few more as well); but more importantly, they are linked to such a multifarious variety of possible "causes" that we finally are unable to say more than that they are contingent; nevertheless-and this is the decisive point-they are factual.

Referring to contingency as the "black hole" of causal discourses-the site we conceptually assign to all those items which are, for the time being, inexplicable-may, however, be somewhat unsatisfactory. From the 1980s onward, the word has evolved into a catch-all term for all sorts of complex items which cultural theoreticians do not deem worth the effort of further reflection. This inclines me to hazard another metaphor-apart from the basic image of the "net" which informs this entire study-in order to overcome at least partly the state of a complete nescio (William Occam), ${ }^{557}$ which one frequently tries to

555 I am referring to Auerbach's theorization of "Christian" realism in his famous book titled Mimesis (which is indebted to Hegel's remarks on "die romantische Kunstform" [part III of his Vorlesungen über die Ästhetik (1835-38)] and to Victor Hugo's "Préface de Cromwell” [1827]).

556 Let me stress that this feature is specific; the formal organization of the Quran is different. 557 As to this basic nominalist confessio, see William Occam, Super quattuor libros sententiarum subtilissimae quaestiones earumque decisiones (1317-1318), I, dist. 38, q. I ("Potest tamen dici quod ipse Deus, vel divina essentia, est una cognitio intuitiva, tam sui ipsius quam omnium aliorum factibilium et infactibilium, tam perfecta et tam clara quod ipsa etiam est notitia evidens omnium praeteritorum, futurorum et praesentium. [...] tenendum est quod Deus evi- 
veil by applying the learned term of "contingency": One might consider the various determinant factors described above according to planetary constellations such as the solar system. This system consists of more and of less important (large) stars. There is one star which seems to be the center (the sun). But this is only an apparent "fact". Considered in a more penetrating way, this "fixed star" reveals itself to be nothing but a mobile object, albeit in constellations that transcend the limits of our solar system. But the most important point which makes me suggest this metaphor in more than just a frivolous manner is the fact that the stability of the system is guaranteed by nothing other than the mutual physical attraction existing between all of its components. If one eliminated only one of the smaller components, the entire system would collapse. It is thus senseless to argue that the sun is the "truly" decisive player within this system; if a seemingly dependent celestial body such as the moon were destroyed, the Earth would be destabilized, all living organisms would disappear, and our globe would be decomposed into fragments or absorbed by larger bodies, which would then be absorbed by the sun, which would in turn be absorbed by larger stars (etc.).

In culture as well, there are quite a few separable determinant factors which constitute the system as a whole, as in the case of planetary systems; and there are factors which at first sight seem to be more important than others. But finally, it turns out that all these factors are able to play their conditioning roles only because the system exists as a whole. ${ }^{558}$ And it seems to be in particular this latter feature-the dependency of these various factors on their being items of a structure, their relational "essence"-which accounts for the fact that they might change their concrete places in the structure in question, ${ }^{559}$ leading to a constant reconfiguration of apparently "fixed" systems.

7.-The date of 1453, mentioned at various occasions in the course of my argument, brings me to a corollary point regarding ideology which I would like to

denter cognoscit omnia futura contingentia. Sed modum exprimere nescio." / "It could nevertheless be said that God himself, or the divine essence, is one single intuitive cognition both of himself and of every other thing, feasible or infeasible, so perfect and so clear that it is itself an evident notion of everything past, future, and present. [...] It is to be held indubitably that God knows all future contingencies certainly, but in a way which I am not able to express.”). 558 In order to avoid misunderstandings: this latter metaphor must not be mixed with the metaphor of the net, which is here applied to explain the internal logic of processes of exchange occurring within the system of culture. The planetary system metaphor is meant to (partly) elucidate the relationship between the diverse "fields" (champs discursifs, in Foucault's terminology) by which we usually compartmentalize the undifferentiated unit of "culture".

559 -which, within cosmic time frames, applies to planetary systems as well. 
make with respect to the "me too" or "we too" attitude-a point which starts from the observation that this attitude, along with the discourses linked to it, is mainly professed by Western intellectuals who work on the "subaltern" cultures in question, or by scholars from these countries who have become completely assimilated and integrated into Western academia, to the extent that it would be devoid of sense to conceive of these people as non-Westerners, as "other".

I am inclined to say that it is, in the final analysis, nothing other than unconscious racial thinking which constitutes the basis of the discourses targeted by me. The somewhat "generous", but in essence condescending basic gesture with which these discourses postulate that "they too", the "subaltern" cultures, developed cultural practices similar to the ones existing in the West, implies that these Western practices "belong" to us, that is, to present-day Western people, that they are "our" intellectual property, quite like the blueprints for our industrial products. But who wrote Oidipous tyrannos (fifth century BCE)? Who wrote Iphigeneia he en Aulidi (fifth century BCE)? Who wrote Hamlet; who wrote Phèdre; who wrote the Wallenstein trilogy (1799), or Faust (1808)? At least as far as I am concerned, I have to say that it was neither me nor any one of "my" ancestors. But, a Herderian may object, my ancestors may perhaps have contributed to the production of these works, in particular in the case of Wallenstein and Faust, by partaking in the process of narrating and renarrating, stretching over several millennia, that finally led to the written texts that have come down to us. The somewhat vague information I am able to gather from the extant records, however, makes it extremely improbable, at least as far as this part of the world, Northern Central Europe, is concerned, that there ever was a stable relation between spaces and tribes residing in these spaces lasting for more than a century.

Traditions are a mix of heterogeneous materials; homogeneity is a projection a posteriori. Consequently, there is nothing I (or the overwhelming majority of present-day Western people) am entitled to be proud of when reading the plays mentioned or seeing them on stage, all the more as the fact that we are able to receive them is linked to historical contingency, as is best evidenced by the erratic transmission history of some of them. I can legitimately admire them, but that is it. It is by chance that I and my occidental contemporaries were born in this part of the world. There is no personal "merit" at all implied in the fact that our cradles were located in Western Europe or in North America. It is a more difficult question whether or not we are entitled to be proud of our own, personal contribution to the tradition we inherited. But as to the tradition itself, it was bestowed on us; there was no activity on our part involved. Con- 
ceding to "other" cultures that they are equal in "value" to our "own" culture always implies the pretense that there is a substantive link between us as individuals and "our" culture.-Racial thinking is far from having disappeared from our intellectual discourses; under the disguise of multiculturalism and identity politics, it is more virulent than it ever was, except perhaps in the $30 \mathrm{~s}$ and 40 s of the last century.

8.-Finally, I will not refrain from making explicit the extent to which the theorization of processes of cultural exchange suggested in this book is at odds with the central metaphorical concept of postcolonialism, which has become most influential even beyond its field of origin: "hybridization". Like all metaphors derived from biology, the concept is in my view in principle problematic when applied to cultural phenomena, because these are fundamentally different from natural ones-which is a truism, since, if it were otherwise, there would be no necessity to distinguish between natura and nutritura, or, in the field of academic disciplines, between the natural sciences and the humanities. ${ }^{560}$ But the main problem concerning the hybridization concept is a more specific one. Its internal logic implies that there are pre-existing "pure" items, which then become "hybridized" in the course of processes of cultural interaction. ${ }^{561}$ It would be contrary to the basic principles of reason to talk about the

560 For a critical view of present-day attempts to overcome this dividing line, see my "Einige Bemerkungen zum Verhältnis von Geisteswissenschaften und Theorie”, in: Joachim Küpper, Markus Rautzenberg, Miriam Schaub, and Regine Strätling (eds.), The Beauty of Theory. Zur Ästhetik und Affektökonomie von Theorien, München 2013, pp. 19-33.

561 It is amazing to see that postcolonial theory is at least to a certain extent conscious of the problem mentioned above, while at the same time it holds on to the concept of hybridity. In his "Adagio" dedicated to the memory of Edward Said, Homi K. Bhabha quotes Said's resistance to “'essentializations' of natural or cultural ideal-types-the Jew, the Indian, the French-because such 'universals' represent the imperial legacy 'by which a dominant culture eliminated the impurities and hybrids that make up all culture." (Critical Inquiry vol. 31, 2 / 2005, pp. 371-380; here: p. 376; the quote from Said is drawn from Musical Elaborations, New York, NY 1991, p. 52; my italics). In the following sentences, however, referring once again to quotes from Said himself, Bhabha underpins Said's enthusiastic reaction to writers such as Rushdie for the achievement of having introduced "“a particular kind of hybrid experience into English.” (“Adagio”, p. 376; Said, "The Road Less Traveled”, in: Gauri Viswanathan [ed.], Power, Politics, and Culture. Interviews with Edward W. Said, New York, NY 2001, pp. 409-418, quote: p. 416). The only explanation for this paradox of insight and blindness may be implied in what Bhabha says about Said's reasons for rejecting essentialism. They are not primarily descriptive or logical, but political. This applies to postcolonial theory in general. It inscribes itself in the broader trend of Western Marxism in the post-'68 period, when the conviction that either the Soviet Union or Maoist China could yield a model for universal "liberation" waned rapidly. In this moment, it was no longer Marx, Stalin, and Mao who were the idols of Western Marxists. Antonio Gramsci took their place. With his emphasis on the "super-structure", and his claim that it is this part of the entire societal structure, namely: all of culture, that needs to be revolutionized first before 
hybridity of certain ("postcolonial") cultural phenomena without making the claim that there are art forms that are, for example, essentially British, while there are others that are essentially Indian.

In the final analysis, postcolonial theory is bound to the Herderian concept of culture as an instance of "rootedness", which is then supposed to be superseded by the "truly" valuable hybrid works. Rootedness, however, is by necessity nothing but a metaphor; the literal soil, or rather ground, from which artifacts or cultural phenomena originate are people, human beings. If the cultures in question are posited as homogeneous-and if not, it would not make any sense to postulate that their products are "pure"562-there are no barriers left that would prevent a racial subtext from making its way into such a theory of culture. And it does not matter whether this is racial thinking "from above" (the racism of the dominant) or "from below" (the racism of the subaltern), because it is part of the entire political project behind the façade of postcolonialism to invert such hierarchies. As in all revolutionary movements from the French Revolution onward, equality is a postulate for a remote future. In order to secure the revolutionary movement's success, it is necessary to establish a (as it has turned out in the past: never-ending) dictatorial regime of the formerly suppressed immediately after the victory.

the "real" taking over by the revolutionaries can take place, the left started in on its huge attempt at changing the thinking of Western societies, of "constructing" new (conceptual) realities which would then produce new factual realities. As a result of this idealistic turn of leftist thinking and activities, theories inscribing themselves into this "grand project", such as postcolonialism, are not primarily descriptive, but rather, according to their self-conceptualization, performative. They want to bring about the structures they describe. It is not a matter of introducing the concept of hybridity as a descriptively adequate scholarly category, but rather of making use of certain variants of the hybridity concept in the interest of "subversion", of "empowering" the "marginalized", the "subaltern", etc. For these reasons, postcolonial theory has to hold on to the postulate that there is a difference between "regular" hybridity, applying to cultural phenomena of any kind, and "real" hybridity as the dialectics characterizing the cultural situation of the (mainly ethnically defined) subjugated and subaltern, who are to become the rulers after the revolution. Hybridity as a characteristic of cultural artifacts produced in situations of balanced power relations and without any "racial" implications that could be ascribed to the configuration in question (France and Italy in the Renaissance; present-day Western Europe and the US, etc.) is of no interest to postcolonial theory. And the fact that, finally, all of culture is hybrid has to be more or less silenced in order to postulate the political dichotomy of dominators and dominated in the sphere of culture as well.

562 The extent to which postcolonial theory is bound to the assumption of essential divergences becomes apparent in many of Bhabha's famous and ubiquitous formulas, for example in his definition of "third space" as a place of "negotiation of incommensurable differences" (The Location of Culture, London and New York, NY 1994, p. 218; my italics). 
For the reasons mentioned above, culture and cultural artifacts are here theorized as resulting from extremely flexible and varying interactions between a "free" floating and various mechanisms of control that try to "regulate" this free floating and which may produce certain forms of stability assignable to certain periods and certain places, if one only takes the aspect of statistical frequency into consideration. The products resulting from this interplay between free exchange and the attempt to direct cultural production are, however, finally all too diverse for it to be possible to sensibly hold that there are typically British or typically Chinese art forms. All such ideas are, as argued above, to a large extent the results of reverse conclusions of a particularly naivve profile: ${ }^{563}$ a work of art is written in English and portrays "traditional" British culture; for that reason, "Englishness" is taken to be its primary feature when it comes to describing the specificity of the work in question.

Stability, essentiality, and purity are but momentary impressions based on the consideration of certain phenomena at a certain time and place which are then projected on entire spaces and epochs for which, in most cases, they do not apply, at least not in their entirety. It is from such illusionary constructions of substances or essentialities that all theories revolving around the concept of hybridity take their point of departure. Talking about "essential" constellations or, as postcolonial theory does, basing one's own, non-essentialist categories on the assumption that there are previous essentialist categories is ideological. The entire attitude derives from the world of power, its interest is political, and its means are purely rhetorical.

9.-It must be stressed, however, that the dichotomous differences which are the logically necessary prerequisite for the concept of hybridity do exist in the field of power. It makes a difference, indeed, whether a given person is the decapitated or the executioner, the conquered or the conqueror, the dominated or the oppressor. In the sphere of culture, things might be much more complicated. The above remarks on the situation in colonial India ${ }^{564}$ may illustrate the extent to which the assumption-finally based on classical Marxist claimsthat culture is nothing other than a structure reflecting "real" power relations is oversimplified. If one did not know anything about the colonial history of

563 For a more detailed discussion of the problems produced by such (very current) reverse conclusions, see above, pp. $104 \mathrm{f}$. and pp. 253-255.

564 I would like to stress once again that more detailed information may be found in the book by Gautam Chakrabarti; what I here expound in terms of a mere description of the historical phenomena is based on this study (Familiarising the Exotic: Introducing European Drama in Early Modern India). 
the subcontinent and was simply told that the East India Company established its first strongholds in the second half of the seventeenth century, that the British state took control over large parts of the territories in the decades following the mid-nineteenth century, and that the British effectively ruled the country until 1947, one would assume, from such a Marxist perspective, that the latter also tried to colonize the minds of the subjugated by imposing on them the English language and British culture. But this was not the case. For whatever reason, the British benignly neglected the entire field of culture during the largest part of their rule over the subcontinent. In the field of literary culture, it was the above-mentioned, somewhat obscure Russian adventurer Lebedev who first brought its Western variant to India. Later developments in this sphere were not primarily instances of imposition, but derived from the local "demand" for more "Western" literary culture, which originated from the first encounters of the Indian audience with Western-style theater.-The same applies to other instances of culture. The English language was not imposed. No one ever forbade the use of the myriad autochthonous languages. The efforts made by large parts of the Indian population to learn English were motivated by their wish to partake in economic, cultural, and scientific negotiations and developments from which they had been excluded for centuries or even millennia. "European" culture indeed made its way into colonial India, but not by way of a process that emulated the political situation.

I should like to stress that such an irenic or idealizing picture of processes of colonization is certainly not paradigmatic in the sense that it would apply to all comparable situations-quite to the contrary. I have already expressed above that processes of conquest originating from communities with universalistic convictions (my examples were Christianity, Islam, and the secular West of the post-Enlightenment era) typically go along with at times quite brutal processes of transculturation, of implementing one's own culture-the only "right" culture-in the conquered territories. On the other hand, I should like to emphasize that the above-characterized model of the early British in India is not the one and only exception to a general rule. It follows patterns recognizable in developments that are of primary importance in world history. The most prominent of these developments may be the story of our own, Western origins, parts of which were already mentioned: In order to get rid of the danger emanating from incidental barbarian incursions on their territory, the Romans conquered, step by step, Western and parts of Central and Northern Europe. They did not at all harbor the ambition of "romanizing" the locals. They wished to end the unrest at their frontiers. In addition, they wanted, as all conquerors do, some economic return for their military endeavors, so they exploited their colonies. The historically crucial development-neglected to date by the innu- 
merable politicized books on colonization and globalization-occurred when the empire collapsed, for whatever reasons, in the fifth century CE. Not only did the colonized locals preserve the Roman culture and language they had adopted during the centuries of foreign rule instead of throwing off the yoke of an "alien" culture; the "Teutonic" conquerors who had made the imperium collapse also adopted the Roman mode of living. It was not that the Roman conquerors imposed their cultural patterns; it was, in a first step, the conquered who adopted them and, in a second step, the (second-degree) conquerors who adopted the culture of the defeated.-I will not indulge in further speculations regarding the point in question and will leave it at the remark that cultural theory informed by Marxian concepts, that is, the overwhelming quantity of cultural theory extant, is hardly compatible with the history of the culture from which Marxism originated. In many cases, the transfer of culture follows the deployment of power. But in many other cases, including several of world-historical import, it does not. Greece and Rome in classical times would be another example; Christianity and pagan Rome would be a third constellation in which the culture of the subjugated becomes the prevalent pattern. I do not have, for the time being, to suggest a viable alternative to the cultural theory of Marxist provenance; suffice it to say that, from my perspective, the historical ignorance accompanying the never-ending repetition of this pattern in mainstream cultural studies is quite astonishing.

In the sphere of culture, all seemingly essential "differences" are based on merely conceptual accumulations of the endless chain of gradual differences which make up "reality". Metaphors such as "circulation" or movements within "networks" seem to be more adequate for making sense of the specificity of cultural phenomena and processes than metaphors based on the assumption of dichotomies. If there are dichotomies at all in the cultural sphere, they are in almost all cases superimpositions resulting from the intentional instrumentalization of culture for political purposes. Political activities are legitimate; no reasonable person would contest that. But talking about culture while pursuing not descriptive, but rather ideological goals is a strategy that convinces only those who do not need to be convinced, because they are already part of the political project. It is a ritual repetition, that is, a public demonstration of belonging-in this case: to the congregation of the ideologically "correct"which informs most present-day "scholarship". 